\section{Gradience in prosodic representation: vowel reduction and neoclassical elements in Brazilian Portuguese}

\section{NATÁLIA BRAMBATTI GUZZO (D) GUILHERME DUARTE GARCIA (1)}

*Author affiliations can be found in the back matter of this article

\section{Glossa}

a journal of general linguistics
RESEARCH

\section{]u[ubiquity press}

CORRESPONDING AUTHOR:

\section{Natália Brambatti Guzzo}

McGill University, Department of Linguistics, CA

nataliaguzzo@me.com

\section{KEYWORDS:}

neoclassical elements; phonological word; vowel reduction; prosodic recursion; Brazilian Portuguese

TO CITE THIS ARTICLE: Guzzo, Natália Brambatti and Guilherme Duarte Garcia. 2021. Gradience in prosodic representation: vowel reduction and neoclassical elements in Brazilian Portuguese. Glossa: a journal of general linguistics 6(1): 74. 1-26. DOI: https://doi. org/10.5334/gjgl.1413 


\section{Introduction}

One of the premises of Prosodic Phonology is that phonological processes apply in reference to prosodic domains, which are arranged into a scale or hierarchy (e.g., Selkirk 1980, 1984, 2011; Hayes 1989; Nespor \& Vogel 1986). In these domains, segmental and stress phenomena, as well as phonotactic constraints, apply. Higher domains (such as the phonological word, the phonological phrase and the intonational phrase) are assumed to result from the indirect mapping of morphosyntactic structures.

It has been proposed that certain structures do not have a fixed prosodic representation, but rather are assigned a particular representation depending on contextual constraints. For example, monosyllabic function words in English (such as at and the) correspond to syllables that cliticize to a phonological word (PWd) when unstressed, but are separate PWds when under focus (compare, e.g., the boss with THE boss; Selkirk 1996). In this case, information structure affects whether the function word is prosodized as a clitic or as a PWd. However, it may also be the case that a given element is prosodized differently depending on the structure with which it combines. In this situation, each form of prosodization for this element should exhibit a particular phonological behavior.

In this paper, we focus on the prosodic representation of neoclassical elements (NCEs), a pseudomorphological class that is crosslinguistically assumed to have multiple prosodic representations (see e.g., Peperkamp 1997b for Italian). NCEs are items of Greek or Latin origin, such as $p \operatorname{sych}(o)$ and electr(o). Although NCEs are relatively productive in many European languages, they are typically found in erudite constructions. Unlike native stems and affixes, NCEs do not seem to have a fixed position in word structure, being found both in initial and final position (compare philosophy and Francophile, both with the NCE phil(o); Bauer 1998; Lüdeling et al. 2002). We examine the phonological behavior of NCEs in initial position in Brazilian Portuguese (BP), since in this language NCEs have been proposed to prosodize differently depending on the structure with which they combine (e.g., Silva 2010; Toneli 2014).

As in other European languages, NCEs in BP may or may not combine with elements that correspond to a lexical word on their own. For example, the NCE psico may attach to a word like linguística 'linguistics', yielding psicolinguística 'psycholinguistics', or it may attach to a non-lexical word like logia, yielding psicologia 'psychology'. In previous analyses (e.g., Silva 2010; Toneli 2014), items like psicologia are assumed to correspond to simple PWds. In other words, the NCE is integrated into the PWd along with the adjacent element. In items like psicolinguística, on the other hand, the NCE and the following element are each assumed to correspond to an independent PWd. In this paper, we refer to structures such as psicologia as NCE + Dep(endent), since the element following the NCE does not have lexical word status, and structures such as psicolinguística as NCE + Indep(endent), since the element following the NCE is an independent lexical word. In NCE + Dep, the element following the NCE may be another NCE itself (such as logia in psicologia).

Analyses that argue that NCE + Dep and NCE + Indep are prosodized differently thus assume that, in NCE + Indep, there is a PWd boundary between the NCE and the following element. In this case, PWd-boundary phenomena should be observed either at the right edge of the NCE or the left edge of the following element. In BP, one phenomenon that is consistently associated with the PWd is word-final vowel raising, in which underlying upper mid vowels (/e, o/) are reduced to high ([i, u]) in unstressed final position (Bisol 2005; Silva 2010; Guzzo 2018). Given the proposed representations for NCE + Dep and NCE + Indep, word-final raising should be displayed by NCEs in NCE + Indep (psicolinguística: [psikullij'gwist]ika]), but not by NCEs in NCE + Dep (psicologia: *[psikulo'zia]).

However, BP also has PWd-internal vowel reduction processes whose surface outcome is similar to word-final raising. These processes are vowel harmony (a pretonic upper mid vowel becomes high when there is a high vowel in the following syllable) and pretonic raising (a pretonic upper mid vowel raises to high without a following high vowel). If NCE + Dep corresponds to a simple PWd, the NCE-final vowel is in pretonic position and is therefore subject to PWd-internal raising processes. The question that arises is whether different prosodic representations can actually be proposed for NCE + Dep and NCE + Indep based on the application of vowel raising, given that the NCE-final vowel in both NCE + Indep and NCE + Dep may undergo reduction. 
We argue that NCE + Dep and NCE + Indep are in effect prosodized differently in BP, and that what reveals these different forms of prosodization is not the presence or absence of vowel reduction, but rather the extent to which reduction is accepted and produced by speakers in structures with NCEs. Specifically, reduction in NCE + Indep (corresponding to word-final raising) should be more acceptable than reduction in NCE + Dep (corresponding to vowel harmony and pretonic raising). In addition, this difference should be reflected in production. That is because while word-final raising is assumed to be categorical in PWd-final position in standard BP (e.g., Leite \& Callou 2002), PWd-internal vowel raising is highly constrained in the language (Oliveira 1992; Bisol 2009), as discussed below.

To examine this issue, we analyze native speakers' judgements of vowel reduction in NCE-final position in both NCE + Dep and NCE + Indep, as well as production data. We show that speakers' judgements and productions are consistent with having different forms of prosodization for NCE + Dep (as a single PWd) and NCE + Indep (as two PWds). Given the non-categoricity of speakers' judgements, and the fact that reduction (at least PWd-internally) applies variably, our results suggest that prosodic differences may also be identified on the basis of gradient behavior-we employ the term gradience to refer to the non-categorical application of a given phonological process. Following from this, analyses that do not account for gradience might assume that, if reduction is allowed in both NCE + Dep and NCE + Indep, then both structures have the same prosodic representation. A consequence of this assumption is that reduction in both structures would be analyzed as word-final raising (with NCE + Dep and NCE + Indep both corresponding to constructions with two PWds), or as raising in pretonic position (with NCE + Dep and NCE + Indep both corresponding to simple PWds). On the other hand, an analysis that accounts for gradient process application is able to capture the observation that NCE + Dep and NCE + Indep undergo different vowel processes that apply at different rates.

This paper is organized as follows. In section 2, we discuss vowel reduction processes in BP, the morphological behavior of NCEs, and the ways in which NCEs seem to be prosodically mapped in the language. Section 3 describes our experimental methods, and section 4 describes our results. We discuss the implications of our results for prosodic representation in section 5 . Section 6 concludes.

\section{Background}

\subsection{Vowel reduction in Brazilian Portuguese}

BP has several vowel processes. Some of these processes ensue from the vowel inventory being reduced in unstressed positions, or from certain contrasts being irrelevant in these positions. In primarily stressed position, Standard BP has seven vowels: a, $\varepsilon, \mathrm{e}, \mathrm{i}, \mathrm{\jmath}, \mathrm{o}, \mathrm{u}$. In pretonic position, the inventory is reduced to five segments: a, e, i, o, u (Câmara Jr. 1970; Wetzels 1992). Standard $\mathrm{BP}$ allows lower mid vowels $/ \varepsilon$, כ/ only in primarily stressed syllables. In derived words where stress shifts from the lower mid vowel to the suffix, the lower mid raises to upper mid-see (1), yielding the reduced inventory for pretonic position. ${ }^{1}$

$$
\begin{array}{ll}
\text { a. 'bellu } & \text { béleza } \\
\text { 'beautiful' 'beauty' } & \\
\text { b. 'mọli mo'leza } & \text { mofl' 'softness' }
\end{array}
$$

In unstressed final position, the inventory is reduced to three vowels: a, i, u (Câmara Jr. 1970). The quality of vowel segments varies somewhat depending on their position. Unstressed final /a/ has been shown to be higher and shorter than its stressed or pretonic counterparts (Major 1985; Fails \& Clegg 1992; Kenstowicz \& Sandalo 2016). Regarding surface [i, u], different analyses obtained slightly distinct results, with some showing that formant values are relatively similar in stressed and unstressed positions (e.g., Fails \& Clegg 1992), and others suggesting that final high vowels are more centralized than their stressed or pretonic counterparts (e.g, Massini-Cagliari 1992). Given these observations, unstressed final vowels are often transcribed

1 Some BP dialects exhibit variable lowering in pretonic position, triggered by a following lower mid or low vowel (e.g., [bolóta] 'ball'; Callou et al. 2002). 
as $[\mathrm{e}, \mathrm{I}, \mathrm{v}]$. Here, we transcribe high and low BP vowels with the same phonetic symbols for all positions for the sake of consistency.

Three vowel processes are of interest for this paper, since they have been used in the identification of prosodic domains in BP. These processes are vowel harmony, pretonic raising, and word-final raising (see e.g., Bisol \& Veloso 2016; Bisol 2009). Although these processes are governed by different conditioning factors, they yield similar surface forms. For this reason, we refer to them more generally as vowel reduction processes. As we will see in what follows, while reduction resulting from word-final raising is assumed to be categorical (in most BP dialects), reduction resulting from vowel harmony and pretonic raising is both phonologically and lexically constrained.

We start by examining vowel harmony in BP. This process involves the raising of pretonic /e, o/ when there is a high vowel (/i, u/, usually stressed) in the following syllable (Bisol 1981; Battisti 1993; Bisol \& Veloso 2016)—see (2). It is observed in virtually all dialects of BP. Crossdialectally, vowel harmony is variable, in the sense that the same speaker may or may not apply it, that different speakers of the same community may apply it at distinct rates, and that different communities may display different application rates (e.g., Bisol 1981; Oliveira 1992). In addition to its phonological conditioning, vowel harmony is lexically constrained, since it seems to apply categorically in some specific lexical items, and be blocked (or rarely apply) in some other items (Oliveira 1992)—see (3).

$$
\begin{aligned}
& \text { a. kóruza } \rightarrow \text { kún'ruza } \\
& \text { b. bó'nitu } \rightarrow \text { bu'nitu } \\
& \text { c. mé'ninu } \rightarrow \text { mi'ninu } \\
& \text { d. pér ruka } \rightarrow \text { píl'ruka } \\
& \text { b. kó 'riza } \rightarrow \text { ?kü'riza }
\end{aligned}
$$

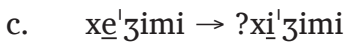

$$
\begin{aligned}
& \text { d. } \quad \text { pe'nuzẽ̃̃ } n \rightarrow \text { ?pi'nuzẽ̃̃ }
\end{aligned}
$$$$
\text { (3) a. mólusku } \rightarrow \text { ?múl'lusku }
$$

Rates of application for vowel harmony seem to be low to moderate. Studies focusing on various BP dialects obtained application rates between 20\% and 40\% (e.g., Bisol 1981; 1989; Battisti 1993; Callou et al. 1991; Callou et al. 2002; Graebin 2008; Schwindt 2002). Some of these studies examined the dialect spoken in the metropolitan area of Porto Alegre, the region of origin of all participants included in our production study and in Version A of our judgement task (Bisol 1981; 1989; Battisti 1993; Schwindt 2002).

Pretonic raising applies when there is no following high vowel. Here, the affected vowels are also /e, o/. This type of raising seems to be mostly conditioned by lexical factors. ${ }^{2}$ Specifically, a few word families and lexical items seem to display pretonic raising categorically, at least for some speakers and/or in certain dialects (e.g., Oliveira 1992; Bisol 2009)—see (4). ${ }^{3}$ Regarding cross-dialectal differences, some dialects seem to exhibit pretonic raising more frequently than others (see Oliveira 1992), but the process seems to apply at low rates overall. In southern dialects (including the one spoken in Porto Alegre), the application rate for pretonic raising is between 5\% and 20\% (Bisol 2009).

$$
\begin{aligned}
& \text { a. bó } \int e \int a \rightarrow \text { bu }{ }^{\prime} \int e \int a \\
& \text { b. kotógelu } \rightarrow \text { kútútvelu } \\
& \text { c. té zowra } \rightarrow \text { t } \underline{\underline{i}}^{\prime} \text { zowra } \\
& \text { d. deva'gar } \rightarrow \text { dżiva'gar }
\end{aligned}
$$

'cheek'
'elbow'
'scissors'
'slowly'

Although analyses of vowel harmony and pretonic raising are usually performed from a traditional variationist approach and do not include formant measurements, the vowels resulting from these processes are assumed to have the same quality as underlying pretonic /i, $\mathrm{u} /$. Both vowel harmony and pretonic raising seem to be socially conditioned to a certain

\footnotetext{
2 Oliveira (1992) argues that, since both vowel harmony and pretonic raising are lexically conditioned, they are not separate phonological processes in BP.

3 As the examples in (4c), (4d), (5b) and (5d) illustrate, /t, d/ are realized as [t $\mathrm{f}, \mathrm{d} 3$ ] before a high front vowel or glide in Standard BP.
} 
extent (e.g., they seem to be favored by speakers in older age groups; Callou et al. 2002). However, neither process seems to be socially stigmatized-for lexical items that are frequently targeted by harmony or raising, process application is observed in speech communities as a whole rather than in a socially stratified way, and seems to be restricted to common lexical items and avoided in erudite forms (Oliveira 1992).

Vowel raising in pretonic position (regardless of whether or not it corresponds to vowel harmony) is a PWd-internal phenomenon in BP, for the following reasons: (a) the affected vowels are part of the stem, and (b) prefix vowels are immune to the phenomenon (Schwindt 2001; Guzzo \& Garcia 2020). As we will see shortly, we treat both forms of raising in pretonic position as part of a single category in our experiments.

In word-final raising, underlying /e, o/ are realized as [i, $\mathrm{u}$ ] in unstressed final position, as illustrated in (5). Word-final raising is a categorical phenomenon in the vast majority of BP dialects (Leite \& Callou 2002), applying at rates above 90\%. Percentages of application above 90\% have also been observed for Porto Alegre (Roveda 1998; Vieira 2002; 2009). Under focus, word-final raising applies variably in BP.

$$
\begin{aligned}
& \text { a. } \quad \int a^{\prime} \text { rope } \rightarrow \int a^{\prime} \text { rop } \underline{i} \\
& \text { b. } \quad \text { pa'rede } \rightarrow \text { pa'redzi } \\
& \text { c. ka'belo } \rightarrow \text { ka'belu } \\
& \text { d. } \quad \text { ves't } \int i d \underline{o} \rightarrow \text { ves't } t \text { idu } \underline{u}
\end{aligned}
$$

As a boundary phenomenon, word-final raising allows the identification of PWds in composite structures. For example, in word-word compounds, each compound element whose stress is not final exhibits word-final raising. This suggests that each element in such compounds corresponds to an independent PWd (Silva 2010; Toneli 2014; Guzzo 2018)—see (6). Another indication of the independent PWd status of each compound member is stress preservation (i.e., each element exhibits stress). Although the structure in (6) does not indicate the prosodic representation of the compounds as a whole, several proposals have been advanced which argue for recursive PWds, composite groups (CGs) or phonological phrases (PPhs) as their domain of prosodization (see Guzzo 2018 for an overview).

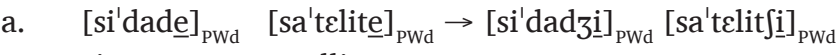

$$
\begin{aligned}
& \text { city satellite } \\
& \text { 'satellite city' } \\
& \text { b. ['pronto }]_{\mathrm{PWd}}[\text { so'koxo }]_{\mathrm{PWd}} \rightarrow[\text { 'prontu }]_{\mathrm{PWd}}[\text { so'koxu }]_{\mathrm{PWd}} \\
& \text { immediate aid } \\
& \text { 'emergency room' }
\end{aligned}
$$

The examples in (6) account for compounds formed by a combination of lexical words. BP also allows composite structures with stressed affixes whose phonological profile is similar to the profile of word-word compounds. Regarding word-final raising, it is assumed that compounds with stressed affixes exhibit the process in both of their elements (Silva 2010; Guzzo 2018). The behavior of these affixes regarding word-final raising, as well as the observation that they bear stress, suggest that the elements of structures with stressed affixes also correspond to independent PWds (see (7); Silva 2010; Toneli 2014; Guzzo 2018). (7a) shows a compound with a stressed prefix, while (7b) shows a compound with a stressed suffix.

$$
\begin{aligned}
& \text { a. } \quad[\text { 'vise }]_{\mathrm{PWd}}[\text { prezi'dente }]_{\mathrm{PWd}} \rightarrow\left[{ }^{\prime} \mathrm{visi} \underline{i}\right]_{\mathrm{PWd}}\left[\text { prezi'dent } \int \underline{\mathrm{i}}\right]_{\mathrm{PWd}} \\
& \text { vice president } \\
& \text { 'vice president' }
\end{aligned}
$$

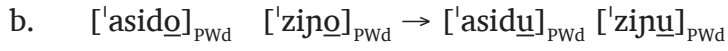

$$
\begin{aligned}
& \text { acid DIM } \\
& \text { 'acidy' }
\end{aligned}
$$

As we will see below, structures of the type NCE + Indep seem to be equivalent to compounds with stressed prefixes in BP, at least from a morphological perspective. Although the morphological status of NCEs is open for debate, NCEs in BP may attach to fully-formed PWds, in the same way that stressed prefixes do. Thus, NCEs that attach to PWds seem to function as prefixes, in which case word-final raising should be observed in the NCE. In NCE + Dep structures, on the 
other hand, there is no lexical word boundary between the NCE and the element with which it combines, and neither the NCE nor the following element are prosodically independent. In this case, there is no context for word-final raising in the NCE. However, as primary stress does not fall on the NCE in NCE + Dep, ${ }^{4}$ vowel raising in pretonic position may apply. Given the status of these reduction processes in BP, speakers' judgements regarding vowel reduction should attain different rates for the two types of NCE structures under examination, and these differences should also be observed in production.

Previous findings seem to support the idea that prosodic structure can be identified on the basis of gradient application of phonological phenomena. In an analysis of clitic prosodization in a southern BP dialect in contact with Veneto, Guzzo \& Garcia (2020) observed that vowel reduction is produced more frequently in non-pronominal than in pronominal clitics, both of which are proclitic in the language. In this dialect, reduction in clitics (as well as in word-final position) applies variably. Like word-final raising, reduction in clitics is an indication that there is a prosodic boundary between the clitic and the following element in BP.

Guzzo \& Garcia (2020) propose that this difference in frequency of application of reduction reflects prosodic differences between non-pronominal and pronominal clitics, which are in turn consistent with certain distinctions in their morphosyntactic behavior. Pronominal clitics (e.g., $s e$ in se machuca 'hurt oneself') can only lean on the main verb of the clause (i.e., they only select one type of host). Lower rates of vowel reduction in these items are thus compatible with the idea that they are more prefix-like (assuming unstressed monosyllabic prefixes, which do not exhibit vowel reduction in BP). Guzzo \& Garcia (2020) argue that pronominal clitics are prosodized with their hosts in the CG. ${ }^{5}$ Non-pronominal clitics (e.g., se in se chover 'if (it) rains'), on the other hand, are morphosyntactically more independent: they attach to hosts of multiple word classes and may be part of non-pronominal clitic strings. Their behavior regarding reduction is consistent with the idea that they attach to their host in a higher prosodic domain relative to pronominal clitics, namely, the $\mathrm{PPh}$.

In the case of NCEs, potential differences in judgement and production of vowel reduction in $\mathrm{NCE}+$ Dep and NCE + Indep should not be due to the same phenomenon applying at distinct rates in two separate prosodic structures. Instead, distinct acceptability rates for raising in pretonic position and word-final raising should be consistent with prosodic differences implied by the application of these processes. Likewise, in production, NCE + Indep should exhibit more reduction (in terms of lower F1 and/or higher F2 values) than NCE + Dep, given the observations for the quality of pretonic and final vowels reported in previous studies (e.g., Fails \& Clegg 1992; Massini-Cagliari 1992). In the next subsection, we examine the morphological categorization of NCEs as well as proposals for their prosodic representation.

\subsection{Neoclassical elements and prosodic representation}

Neoclassical elements are important for the discussion of multiple prosodic mappings since, from a crosslinguistic perspective, they are able to form structures with elements from different categories, such as other NCEs (e.g., psycho-logy) and independent PWds (e.g., psycho-linguistics). NCEs are elements of classical origin (Greek or Latin), and they are used relatively extensively in many languages, including in Romance (such as Portuguese, Spanish and Italian) and Germanic languages (such as English, German and Dutch).

The morphological classification of NCEs has been the object of much debate. It is generally agreed upon that NCEs are learned forms that may have, to some extent, a different morphological behavior from native items (see e.g., Scalise 1986; Bauer 1998). Due to the diversity of structures containing NCEs, these elements have been classified as stems, affixes, and combining forms (for discussion, see Bauer 1998; Lüdeling et al. 2002; Lüdeling 2006).

\footnotetext{
In some NCE + Dep structures, stress does fall on the NCE-final vowel, which surfaces as [o] (e.g., psicólogo [psi'kologu] 'psychologist'). Such structures, however, are not included in our analysis.

5 Guzzo \& Garcia (2020) discard the PWd (either simple or recursive) as the domain of prosodization for pronominal clitics, given differences in phonological behavior that hold between clitics and unstressed monosyllabic prefixes in BP. In their analysis, these prefixes are represented in the PWd. To accommodate the phonological distinctions that exist between pronominal and non-pronominal clitics in this variety of BP, another domain in the prosodic hierarchy (namely, the composite group) appears to be necessary (in line with, e.g., Vogel 2009).
} 
The classification of NCEs as stems has been established on both semantic and morphological grounds: NCEs have specific meanings and may combine with the same affixes as native stems. In English, for example, the form psychology (with two NCEs) can be derived into psychological, with suffixes that can also combine with native stems. Under this view, words like psychology would thus correspond to stem + stem compounds. These compounds would differ from word + word compounds (such as lighthouse or toothbrush) because, unlike word + word compound members, the elements of stem + stem compounds cannot be instantiated on their own (e.g., psycho and logy do not correspond to independent words). ${ }^{6}$

As previously mentioned, NCEs may also attach to lexical items that correspond to independent PWds. This is the case of a structure such as psycholinguistics. In light of these data, NCEs have been considered to be affixes in some accounts. However, the classification of NCEs as affixes implies that structures such as psychology would be formed by two affixes and no stem, which is not observed in native word formation (at least in any of the Romance and Germanic languages that have NCEs).

Given the observation that NCEs may form structures with diverse items (e.g., other NCEs and independent lexical words), and that NCEs do not appear in isolation, they have also been classified as combining forms (e.g., Bauer 1998). Although combining form is not a morphological category per se, this label captures the idea that NCEs behave differently from native stems and affixes, in that they attach to multiple types of structures. ${ }^{7}$ A potential consequence of this behavior for prosodic structure is that NCEs may prosodize differently depending on the type of element with which they form a construction.

As previously mentioned, Prosodic Phonology assumes that phonological phenomena apply in reference to specific prosodic domains (e.g., Selkirk 1984, 1986; Nespor \& Vogel 1986). These domains range from the syllable ( $\sigma$ ) to the intonational phrase (IP), as shown in Figure $1 .{ }^{8}$ While initial accounts assumed that hierarchical domains are exhaustive and non-recursive (e.g., Selkirk 1984; Nespor \& Vogel 1986), more recent approaches allow violations to either Exhaustivity or Non-Recursivity or to both principles (see, e.g., Inkelas 1989; Peperkamp 1997b; Zec 2005; Ito \& Mester 2009; Kabak \& Revithiadou 2009; Blumenfeld 2011; Bennett 2018; among many others; see also Ladd 1986; Wagner 2010). Given these assumptions, multiple prosodic representations may be available to a single item, and its phonological behavior will be different depending on the way it is prosodized.

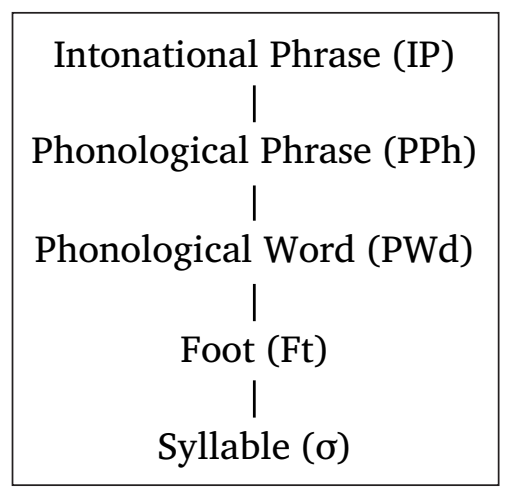

Figure 1 Partial prosodic hierarchy (adapted from Selkirk 1984; Nespor \& Vogel 1986).

\footnotetext{
6 NCEs may be instantiated on their own if they derive from clipping. This is the case, for example, of psycho (for psychopath) in English, and psico (for psicologia 'psychology' or psicólogo 'psychologist') in BP.

7 The SPE (Chomsky \& Halle 1968) does not treat NCEs as a separate morphological category, but suggests that different NCEs may be classified differently depending on what they combine with, which resembles the proposal that NCEs are combining forms. For example, in the SPE, mono and tele are classified as prefixes that can combine with both stems and independent words. The stems with which these prefixes can combine may also be NCEs, such as graph (e.g., monograph).

8 Some accounts also include the mora $(\mu)$ as the lowest domain in the prosodic hierarchy, and the phonological utterance (U) as its highest domain. Other accounts also consider the existence of an additional domain between the phonological word (PWd) and the phonological phrase ( $\mathrm{PPh}$ ). This domain was initially called clitic group (Nespor \& Vogel 1986; Hayes 1989) and later received other labels, such as composite group (Vogel 2008, 2009, 2010) and prosodic word group (Vigário 2010), and its specificities vary in different analyses. Other accounts also include a domain between the foot and the PWd, namely, the colon (Topintzi 2017; Lionnet 2019).
} 
In effect, Peperkamp (1997b, 1997a) suggests that there are two prosodic representations available to constructions with NCEs in Standard Italian, through an examination of stem + word and word + word compounds (such as eurosocialista 'Eurosocialist' and ieri sera 'last night', respectively) in comparison to stem + stem structures (such as filo + sofo 'philosopher'). In this analysis, NCEs are classified as stems. ${ }^{9}$

Both stem + word and word + word compounds behave identically in Standard Italian, in that they do not exhibit intervocalic $s$-voicing, a phenomenon that applies PWd-internally. Stem + stem structures, on the other hand, display this process (e.g., /filo/ + /sofo/ = [filózofo], *[filósofo] 'philosopher'), which supports their prosodization as simple PWds. Both stem + word and word + word compounds are also similar in that, in cases where the leftmost element of the compound has a lower mid vowel, the vowel may be realized as lower mid or raised to upper mid-see (8). In Standard Italian, like in BP, lower mid vowels are only observed in primarily stressed positions, and they are raised to upper mid in derived forms where stress shifts to another vowel. Given the alternation, Peperkamp (1997b, 1997a) proposes that these compounds may be prosodized in two ways: as separate PWds, in which case the lower mid vowel in the leftmost element is preserved (first structure in (8a) and (8b)), and as recursive PWds, in which case vowel raising is observed (second structure in (8a) and (8b)). Note that, in the recursive representation, the first element of the compound has no specific prosodic status.

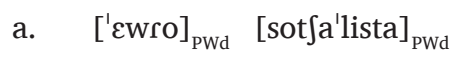

$$
\begin{aligned}
& \text { ['ewro [sot]a'lista } \left.]_{\mathrm{PWd}}\right]_{\mathrm{PWd}}
\end{aligned}
$$$$
\text { 'euro socialist' }
$$

(stem + word compound)
b. $\quad[\text { 'jeri }]_{\mathrm{PWd}}\left[{ }^{\prime} \text { sera }\right]_{\mathrm{PWd}}$
['jeri $\left.[\text { 'sera }]_{\mathrm{PWd}}\right]_{\mathrm{PWd}}$

'last night'

(word + word compound)

The phonological behavior of stem + stem structures and stem + word compounds in Standard Italian suggests that the prosodic representation for NCEs is not fixed. While NCEs in stem + stem structures seem to be part of simple PWds, NCEs in stem + word compounds may correspond to independent PWds or form recursive PWd structures.

Different prosodic representations have also been proposed for NCEs in BP, although in this case these representations mostly rely on the type of item with which the NCE combines. Specifically, NCEs that form a structure with another morphosyntactically dependent item (i.e., an item that does not correspond to an independent lexical word) are arguably prosodized within simple PWds (see e.g., Silva 2010; Toneli 2014). In this case, there is no PWd boundary between the NCE and the element with which it forms a structure. Items such as psicologia 'psychology' (NCE + NCE) and eletrocutado 'electrocuted' (NCE + non-lexical word) are assigned this prosodic representation-see (9). In eletrocutado, the NCE is eletro; the form with which it combines (cutado) does not correspond to a lexical word in BP, and it is not another NCE either. This example illustrates the observation that NCEs may function as stems to which affixes (or pseudo-affixes) are attached (see e.g., Lüdeling et al. 2002). As mentioned above, and in anticipation to the experimental results reported below, we refer to the structures in (9) as NCE + Dep.

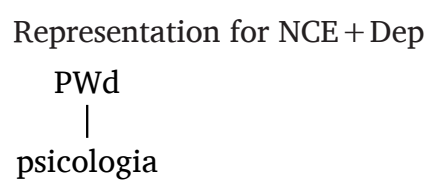

On the other hand, NCEs that combine with independent lexical items (corresponding to PWds) have been proposed to be prosodized as independent PWds, yielding a recursive PWd with the adjacent lexical item (e.g., Silva 2010; see (10)). Items such as psicolinguística 'psycholinguistics' and eletrodoméstico 'household appliance (lit. electro-domestic)' are assigned this representation. Structures such as the one in (10) are those that we refer to as NCE + Indep. 
NCEs in BP have either penultimate stress (e.g., psíco 'psycho', elétro 'electro', hídro 'hydro') or antepenultimate stress (e.g., hétero 'hetero'). NCE + Dep structures exhibit a single primary stress, which respects the trisyllabic window for stress in BP. Thus, in NCE + Dep, stress will fall on the rightmost element (Dep): psicología. In NCE + Indep, on the other hand, each element bears stress: psíco linguística. In this sense, NCE + Indep behaves like stressed prefix + word composite structures in BP, where each element is stressed (e.g., pré escóla 'pre-school', cóntra pónto 'counter argument') (e.g., Silva 2010; see also Guzzo 2018).

Regarding the vowel reduction processes described in the previous subsection, some specific predictions can be made for NCE + Dep and NCE + Indep. In NCE + Indep, the PWd status of the NCE suggests that it is subject to word-final raising, like unstressed final vowels in lexical words corresponding to independent PWds. Thus, structures such as eletrodoméstico and psicolinguística would be produced with raising of the final /o/ in the NCE, as shown in (11). The examples indicate only where the main stress of the structure is.

$$
\begin{aligned}
& \text { a. elctrodo'mest } \int i k o \rightarrow \text { elctrudo'mest } \int i k u \\
& \text { b. psikolin'gwistika } \rightarrow \text { psikulin'gwist } \int i k a
\end{aligned}
$$

'household appliance'
'psycholinguistics'

In NCE + Dep, since there is no PWd boundary between the elements, word-final raising cannot target the NCE. However, in NCE + Dep, an NCE upper mid vowel may be affected by the processes that target pretonic vowels in BP, namely, vowel harmony and pretonic raising. The examples in (12) show how these processes might affect the NCE-final vowel /o/. If a high vowel follows the NCE-final vowel, there is context for vowel harmony, as observed in (12a). If no following high vowel is present, however, the NCE structure might still pattern with other lexical items in the language and exhibit pretonic raising, as observed in (12b).

$$
\begin{aligned}
& \text { a. eletroku'tado } \rightarrow \text { eletrukuku'tadu } \\
& \text { b. } \quad \text { psikolo'zia } \rightarrow \text { psikulo' }{ }^{\prime}{ }^{\prime} \text { ia }
\end{aligned}
$$

'electrocuted' 'psychology'

In summary, NCE + Dep and NCE + Indep exhibit important differences with respect to morphology and stress assignment, which suggests distinct prosodic representations. One question that arises is whether these distinct representations can also be identified based on vowel reduction processes, since the phonetic outcome of these processes is similar. In other words, since reduction might yield both [eletruddo'mest]iku] and [eletruku'tadu], to what extent is reduction a reliable indicator of prosodic representations for NCEs in BP?

As previously discussed, word-final raising is assumed to be a categorical phenomenon in standard BP, while raising in pretonic position is conditioned by phonological and lexical factors. Thus, reduction should target NCE + Dep and NCE + Indep at different degrees: NCE + Indep should yield higher acceptance rates for reduction and should exhibit more reduction in production. Because reduction in NCE + Dep and NCE + Indep can be mapped to distinct phonological processes, these differences in acceptance and production should reflect the separate ways in which these structures are prosodized. To test if this is the case, we conducted two experiments, namely, a judgement task with auditory stimuli where participants rated NCE + Dep and NCE + Indep with and without vowel reduction in the NCE-final vowel, and a production task. We describe these experiments in the next section.

\section{Methods}

To investigate whether speakers' preferences regarding vowel reduction in structures containing NCEs (NCE + Dep and NCE + Indep) reflect what is expected given the proposed prosodic representation for such structures (see (9) and (10)), we designed an auditory judgement task and a production task. In the judgement task, participants rated the naturalness of the 
pronunciation of isolated words. Two versions of the task were developed-we refer to them as Version A and Version B below. In the production task, a subset of participants in Version A of the judgement task produced NCE + Dep and NCE + Indep structures in carrier sentences.

\subsection{Participants}

In both Versions A $(n=10)$ and B $(n=14)$ of the judgement task, participants were native speakers of BP (age range: 17-45 yo). Participants in Version A were tested in Brazil, while those in Version B were tested in Canada. Participants in the production task were a subset of participants from Version A ( $n=5$, three females).

Participants in Version A were all from the metropolitan area of Porto Alegre, in the southern state of Rio Grande do Sul. As previously mentioned, in the dialect of BP spoken in the area of Porto Alegre, word-final raising is assumed to be categorical (e.g., Roveda 1998; Vieira 2002; 2009), and raising in pretonic position applies at moderate rates (between $30 \%$ and $40 \%$ for vowel harmony and around 10\% for pretonic raising; e.g., Bisol 1981; 2009; Battisti 1993). Similar to other BP dialects, both vowel harmony and pretonic raising seem to be lexically constrained in the Porto Alegre dialect (Bisol 2009).

Participants in Version B were tested in Montréal, Canada, and had more diverse backgroundsalthough most were from the southern and southeastern regions of Brazil, where vowel reduction processes apply in similar ways relative to Porto Alegre. To mitigate the possibility of dialectal influence on participants' responses in the judgement task, all participants were told to assume that the words they were about to hear were pronounced by a journalist in a nationally televised news show. Our objective by telling participants this was twofold: (a) we wanted to make sure participants' judgements were based on standard BP (in this case, the variety of BP that is disseminated by the media), and (b) given that NCEs are typically part of learned constructions and therefore may be restricted to specific communication contexts, we did not want participants to be surprised by the presence of structures with NCEs in the data, which could lead them to reject these items (regardless of how they were produced).

All participants had post-secondary education (either complete or under way). Although most participants reported some knowledge of a foreign language (especially English and French), all of them used BP on a regular basis, including for work or study purposes.

\subsection{Stimuli}

For the judgement task, participants rated stimuli that were recorded by a male native speaker of BP with training in phonetics. The stimuli were produced naturalistically, and they were subsequently checked in Praat (Boersma \& Weenink 2020)—we elaborate on this point at the end of this subsection.

The target items were NCEs in NCE + Dep $(n=16)$ and NCE + Indep forms $(n=16)$. For consistency, all NCEs had penultimate stress and ended in /o/ (agro /'agro/, eletro /e'letro/, hidro /'idro/, neuro /'newro/, orto /'orto/, proto /'proto/, pseudo /'psewdo/, psico /'psiko/), which was the vowel under focus. Two versions of each target item were recorded, with and without reduction. Thus, an NCE + Dep form such as psicologia was recorded as [psikolo'zia] and [psikulo' 'zia], and an NCE + Indep form such as psicolinguística was recorded as [psikolin'gwist]ika] and [psikulin'gwist ika]. Examples of target stimuli are provided in Table 1-a complete list is provided in Appendix A.1.10

\begin{tabular}{llll}
\hline NCE+DEP & & NCE+INDEP & \\
\hline [eletroku'tadu] & 'electrocuted' & [eletrodo'mest]iku] & 'household appliance' \\
\hline [idróvia] & 'waterway' & [idrozi'nast $\left.\int i k a\right]$ & 'water aerobics' \\
\hline [psikolo'zia] & 'psychology' & [psikolin'gwist $\left.\int i k a\right]$ & 'psycholinguistics' \\
\hline
\end{tabular}


As previously mentioned, Dep and Indep in NCE + Dep and NCE + Indep refer to whether or not the element with which the NCE combines is an independent lexical item (and PWd). Classifying some NCE structures as NCE + Dep or NCE + Indep may be challenging, as it is not always clear whether the element following the NCE corresponds to an independent lexical or phonological word. For instance, we classify the item hidrovia 'waterway' as NCE + Dep because hidrovia patterns (both morphologically and phonologically) with ferrovia 'railway', which behaves as a single phonological unit-ferrovia results from the combination between ferro 'iron' and via 'way'. However, while the word ferro exhibits a stressed lower mid vowel (['fexu]), in ferrovia the vowel raises to upper mid ([fexo'via]), which indicates that there is no PWd boundary between the two elements of the structure (see section 2.1).

Two of the NCE + Dep structures have context for vowel harmony, namely, eletrocutado and hidrovia. We included these structures in the same category as NCE + Dep structures that might exhibit pretonic raising for two reasons. The first reason is that there is not a substantial number of NCE + Dep structures that offer context for vowel harmony, especially when the element following the NCE is another NCE. The second reason is because of the similarities between vowel harmony and pretonic raising: both are variable and lexically conditioned, and thus their application is more restricted than the application of word-final raising.

Regarding the NCEs that were included in this study, two of them exhibit a lower mid vowel when produced in isolation. That is the case of eletro (/e'letro/) and proto (/'proto/). Production of these NCEs in the stimuli was consistent with the proposed prosodic representations for NCE + Dep and NCE + Indep. Therefore, in NCE + Dep the NCE lower mid vowel raises to upper mid (e.g., [eletroku'tadu]), as per what is observed in pretonic positions in BP (see section 2.1). In NCE + Indep, on the other hand, the lower mid vowel was preserved, in line with the representation of the structure as having separate PWds (e.g., [eletrodo'mest]iku]). Another NCE in our experiment, orto, variably displays a lower mid vowel when produced in isolation. In our stimuli, however, orto was invariably produced with an upper mid vowel, for the sake of consistency.

Fillers in the judgement task included nouns with no NCE in them (e.g., comida 'food', devagar 'slowly'). The number of unique fillers was 47. Filler items were recorded with or without

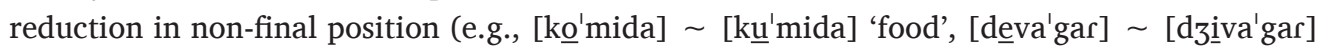
'slowly'). For some filler items, reduction in pretonic position should be acceptable (e.g., comida, devagar), while for others we expected participants to judge them as unnatural (e.g., [3inira'sã $\tilde{w}^{\eta}$ ] for geração 'generation'). Both target items and fillers exhibited word-final raising of upper mid vowels in absolute final position, consistent with the pattern that is expected in standard BP (e.g., [eletrodo'mest]iku] 'household appliance', [pro'gresu] 'progress'). Participants heard some fillers more than once. The total number of fillers was 138 for participants in Version A, and 276 for participants in Version B. The complete list of fillers is provided in Appendix A.2.

To ensure phonetic consistency across forms with and without reduction in both structures with NCEs, first and second formant values, as well as duration and f0, were extracted from the target vowel in the target stimuli. As already noted, reduction in BP word-final vowels has been associated with raising (i.e., lower F1 values; Fails \& Clegg 1992) and centralization (i.e., higher F2 values; Massini-Cagliari 1992). Raising in pretonic vowels, on the other hand, is assumed to yield formant values equivalent to those of pretonic /i, $\mathrm{u} /$. In our stimuli, mostly F1 differentiated reduced from non-reduced vowels, as observed in Figure 2. This difference in formant values in our stimuli is likely more robust than what is found in spontaneous speech, and it is in part the result of careful articulation during the recording of the stimuli. Nevertheless, this difference is a way to ensure categorical discrimination in the judgement task. Regarding duration, [o] is longer than [u] in the stimuli. f0 measurements indicate that [o] had lower f0 than [u] overall.

The same stimuli were used in the production task. Fillers $(n=32)$ included words with four or more syllables, so that target items and fillers could not be differentiated based on word length. Participants trained with a few fillers before recording their productions. 


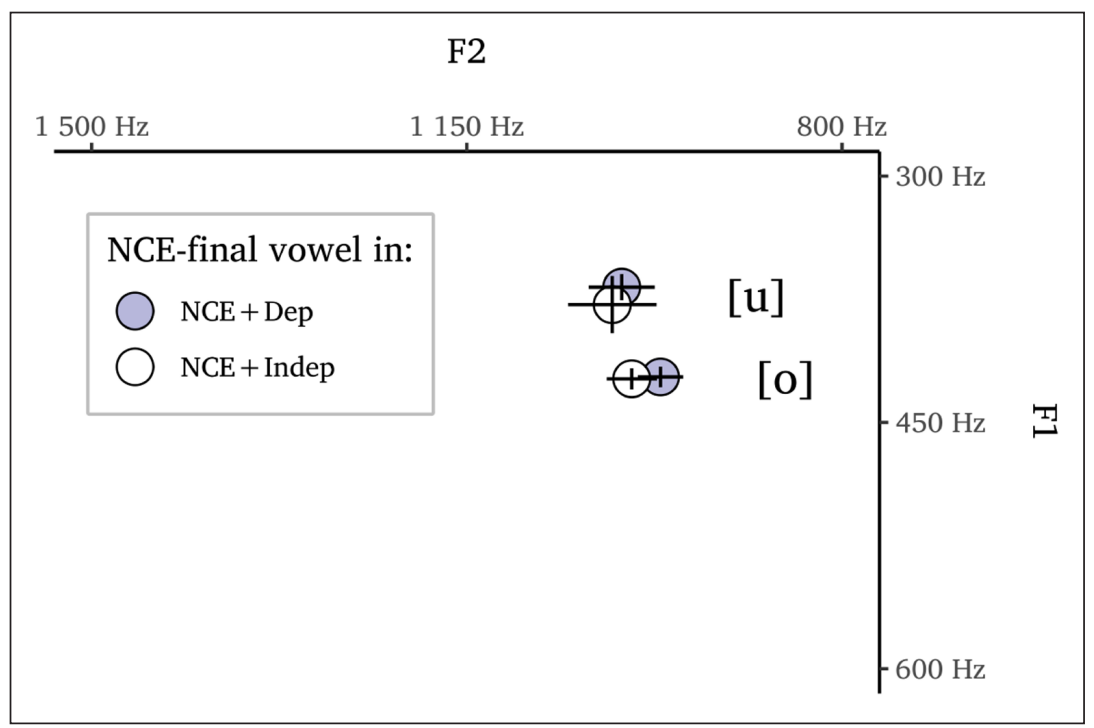

\subsection{Procedure}

\subsubsection{Judgement task}

We investigated speakers' preferences regarding vowel reduction in NCEs by means of a judgement task designed in Praat (Boersma \& Weenink 2020). Stimuli were pseudo-randomized and presented to participants one at a time, after a beep. Participants were able to see the orthographic form of the item they were judging, and were instructed to rate how natural the stimuli sounded using a 10-point scale ( 1 = completely unnatural, $10=$ completely natural). Participants heard the stimuli through headphones and rated the words using the laptop keyboard.

Participants in Version A rated each item (with and without reduction) twice. To ensure that seeing each item twice did not affect participants' responses, the experiment was shortened in Version B, and each item (with and without reduction) was rated once. Thus, participants in Version A rated a total of 404 items, while those in Version B rated 202 items. Version B is therefore a replication of Version A.

As we will see below, there was no difference between the two versions of the experiment, which suggests that neither the repetition of the stimuli nor the length of the experiment affected responses. Likewise, because both versions yielded the same results, we can rule out extralinguistic factors (such as place of origin or exposure to a second language) as potential biases in speakers' preferences in our experiment. Participants in Version A took approximately 30 minutes on average to complete the experiment (they were allowed to take a five-minute break halfway through it). Participants in Version B took on average 15 minutes to complete the experiment (without any breaks). Participants were tested in a silent room.

\subsubsection{Production task}

For the production task, participants were asked to read short dialogues (of the type question + answer), which were presented using slides. Two types of dialogues were included, to test for the potential effect of focus on vowel quality (see discussion in Vogel et al. 2015). Stimuli were therefore produced in focus and non-focus positions in the answer portion of the dialogues-see examples in (13) and (14), where X represents a given stimulus. In the nonfocus condition, the target constructions were produced both in the question and the answer, but only the production in the answer was measured. As previously mentioned, the target stimuli were the same NCE structures used in the judgement task, and participants trained with a few items before recording. The stimuli were pseudo-randomized.

a. $\mathrm{O}_{\mathrm{que}}$ a Maria falou durante a aula? What $_{F}$ the Mary said during the class? 'What ${ }_{F}$ did Mary say during class?'

b. A Maria falou $\mathrm{X}_{F}$ durante a aula. The Mary said $\mathrm{X}_{F}$ during the class. 'Mary said $\mathrm{X}_{F}$ during class.' 
a. A Maria falou $\mathrm{X}$ depois $_{F}$ da aula? The Mary said $X$ after $_{F}$ of the class? 'Did Mary say X after ${ }_{F}$ class?'

b. Não, a Maria falou $X$ durante $_{F}$ a aula, não depois da aula. No, the Mary said $X$ during $_{F}$ the class, not after of the class. 'No, Mary said X during ${ }_{F}$ class, not after class.'

Participants were recorded in a silent room using a TASCAM DR-07MKII Portable Digital Recorder. Later, the target vowels in the sound files were manually segmented using Praat. F1 and F2 values as well as vowel duration were extracted using a script.

\subsection{Predictions}

As previously mentioned, our goal is to examine whether vowel reduction patterns in structures with NCEs (NCE + Dep and NCE + Indep) are consistent with the prosodic representations that have been proposed for them-see (9) and (10). Therefore, we predict the following for the judgement task:

i. If NCE + Dep and NCE + Indep have distinct prosodic representations, there should be a difference in how they are rated for vowel reduction.

ii. If NCE + Dep and NCE + Indep are indeed rated differently, reduction should be more natural in NCE + Indep than in NCE + Dep, since reduction in NCE + Indep corresponds to word-final raising, which is categorical in PWds in BP. Reduction in NCE + Dep should attain moderate ratings. Since raising in pretonic position is limited but possible (being constrained by both phonological and lexical factors), speakers should find it acceptable but not as natural as reduction in NCE + Indep. In addition, reduction in NCE + Dep should be less acceptable given the avoidance in production of raising in pretonic position in erudite forms.

iii. Since NCEs are erudite items and the orthographic form of the stimuli was presented to the participants, non-reduction should be rated highly for both NCE + Dep and NCE + Indep. Given the possibility that participants may have seen some of the target NCE structures only in writing, they should accept productions that are faithful to their orthographic forms.

For our production task, we predict that NCE + Indep should yield more reduction of the target vowel relative to NCE + Dep. That is because the target vowel of the NCE is in final position in NCE + Indep and in pretonic position in NCE + Dep. The target vowel in NCE + Indep should therefore exhibit one or more of the signature cues for reduction in word-final position: (a) higher F2 values (centralization), (b) lower F1 values (raising), and/or (c) shorter duration. On the other hand, given that raising in pretonic position is lexically conditioned and associated with non-erudite words (Oliveira 1992), NCE + Dep words should exhibit less reduction relative to NCE + Indep words.

\subsection{Statistical analysis}

Besides being coded for NCE + Dep $v s$ NCE + Indep as well as reduction $v s$ non-reduction, the target items used in the judgement task were also coded for preceding and following vowel and consonant qualities. The model we report in section 4 does not include vowel and consonant qualities as predictors, since their effects are either not statistically credible or inconsistent across conditions. For instance, a small effect of following vowel exists in the data-a low vowel is correlated with better ratings relative to a high vowel (e.g., [idrogra'fia] $>$ [idro'via]). However, such an effect is only found for non-reduced forms, which makes little linguistic sense for the data in question.

The model we report below for the judgement data also conflates both versions (A and B) of the experiment. We do that because both groups of participants exhibit practically the same patterns in their responses, as we will see shortly. Crucially, a model including both vowel quality and experiment version as predictors has a fit that is not statistically better than a model that does not include these predictors-goodness of fit was assessed based on WAIC 
(widely applicable information criterion) values ${ }^{11}$ (Watanabe 2013; Gelman et al. 2014) and their associated standard errors. Lastly, we should note that different models were run with different codings for preceding and following vowels and consonants. For example, in one model we dichotomized vowel quality based on their height (low $v s$ high) as opposed to the raw vowel qualities coded for in the data. In yet another model, we coded consonants based on their sonority (sonorants $v s$ obstruents). Whether or not such variables are included in a model, the same effects of interest are confirmed (i.e., NCE + Dep vs NCE + Indep, as we will see below).

We analyze our judgement and production data using Bayesian hierarchical ordinal and linear regressions, respectively, with uninformed priors using Stan (Carpenter et al. 2017) in R ( $R$ Core Team 2020). Given our priors, the estimates provided in our analysis are very similar to those generated by an equivalent Frequentist model. The difference is that our models provide entire posterior distributions of effect sizes given the data, $P(\hat{\beta} \mid$ data $)$, as opposed to single point estimates, $P($ data $\mid \hat{\beta})$. Further, variance is not assumed to be constant across variables (i.e., homoscedasticity). Finally, Bayesian models provide a much more intuitive interpretation when it comes to credible intervals (cf. confidence intervals).

Because Bayesian inference estimates the probability of parameter values given the data, $P(\hat{\beta} \mid$ data $)$, we report complete posterior distributions of credible parameters values in section 4, accompanied by 50\% and 95\% highest density intervals (HDI). Unlike Frequentist confidence intervals, HDIs are probability distributions. Simply put, values that are closer to the center of the distribution are more credible given the data than values that are far from the center of the distribution-we assume Gaussian distributions for parameter values throughout the paper. As a decision tool, we can assume that if zero is a credible parameter value located within a given HDI, we can't be statistically certain that a credible effect exists in the dada being modeled. Note, however, that our inference is affected by where in a HDI zero is located (cf. confidence intervals). We return to this discussion in section 4, where we examine our model's estimates and their posterior distributions.

\section{Results}

\subsection{Judgement data}

Figure 3 shows participants' responses in Version A and Version B separately. ${ }^{12}$ On the $x$-axis, we see NCE + Dep and NCE + Indep stimuli, and on the $y$-axis we see the average response along our 10-point scale-bootstrapped standard errors are also provided. The mean responses for items with reduction are indicated with a circle, and the lines represent by-speaker averages. As we can see, participants in Versions A and B behave strikingly similarly, insofar as both groups prefer reduction in NCE + Indep forms to reduction in NCE + Dep forms. ${ }^{13}$

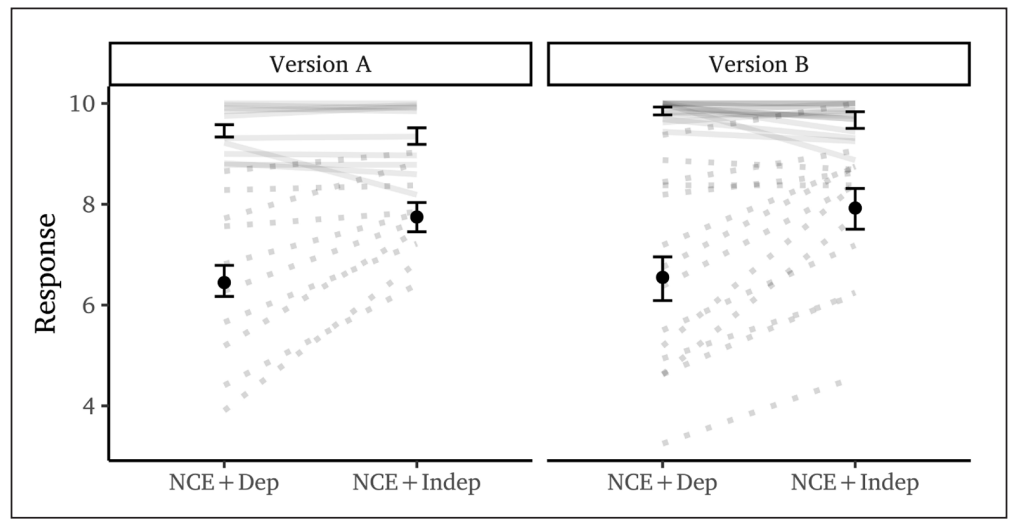

11 WAIC is a fully Bayesian method of assessing the fit of a Bayesian model. The method consists of taking averages of the log-likelihood over the posterior distribution-cf. DIC (deviance information criterion), which uses point estimates. WAIC takes into account individual data points, and is computationally convenient (faster) when compared to cross-validation. Simply put, models with lower WAIC values offer a better fit to the data.

12 We have also plotted the data without the stimuli containing eletro and proto. As previously mentioned, these NCEs are produced with a lower-mid vowel in stressed position in NCE + Indep, which might impact participants' judgements. Since the results remained the same, these items were kept in the analysis.

13 We also examined participants' judgements for the fillers, based on whether or not reduction should be accepted in them. In items where reduction is expected to be natural, participants' mean rating for reduction was 7.7, while in items where it is expected to be unnatural, the mean rating was 3.3. Participants in both versions behaved similarly.
Figure 3 Mean responses from Version $A$ and Version $B$ along 10-point scale and associated (bootstrapped) standard errors. Items with reduction are represented with "๑"; dotted lines represent byspeaker means for items with reduction. 
Figure 4 conflates both versions of the experiment and displays the concentration of raw responses for each of the 10 points along our scale. The bars represent the scale used by participants, and each color represents one of the ten points along the scale: the lower end of the scale ("unnatural") is represented by darker colors, while the upper end of the scale ("natural") is represented by lighter colors. Means are provided in boxes.

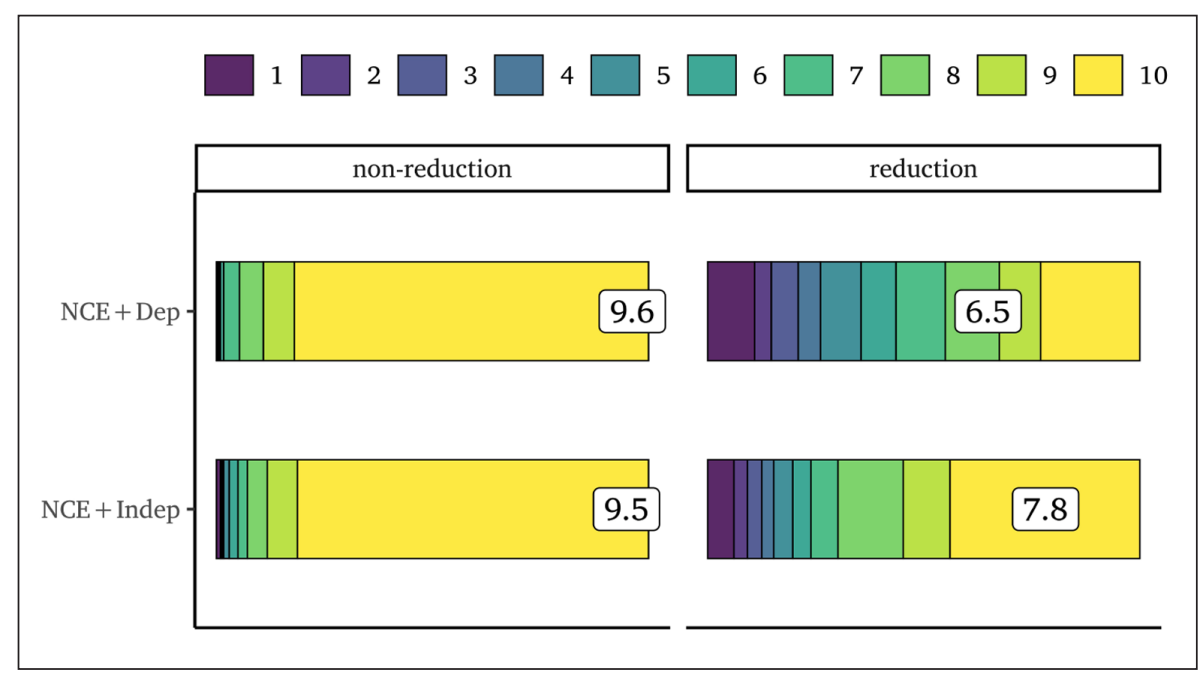

The model we report includes reduction and type of NCE structure as main effects, and an interaction between these predictors, as shown in Figure 4. In addition, following Barr et al. (2013), our model has a by-speaker random slope for the interaction in question, as well as a by-item random intercept. The model estimates are provided in Figure 5, which presents the posterior distributions of the effect sizes in question-the model specification is shown at the top of the figure. Each distribution in Figure 5 also shows the 50\% and 95\% HDIs, the random effects by speaker, and values for the mean estimate accompanied by the 95\% HDIs on the right-hand side. Given that the model in question is ordinal (cumulative link function; logit), and that our response variable is a 10-point scale, $n-1$ threshold estimates are also generated by the model (see Table 4 in Appendix A.3). For the model in question, four chains were used with 8,000 iterations each (2,000 iterations for warmup).

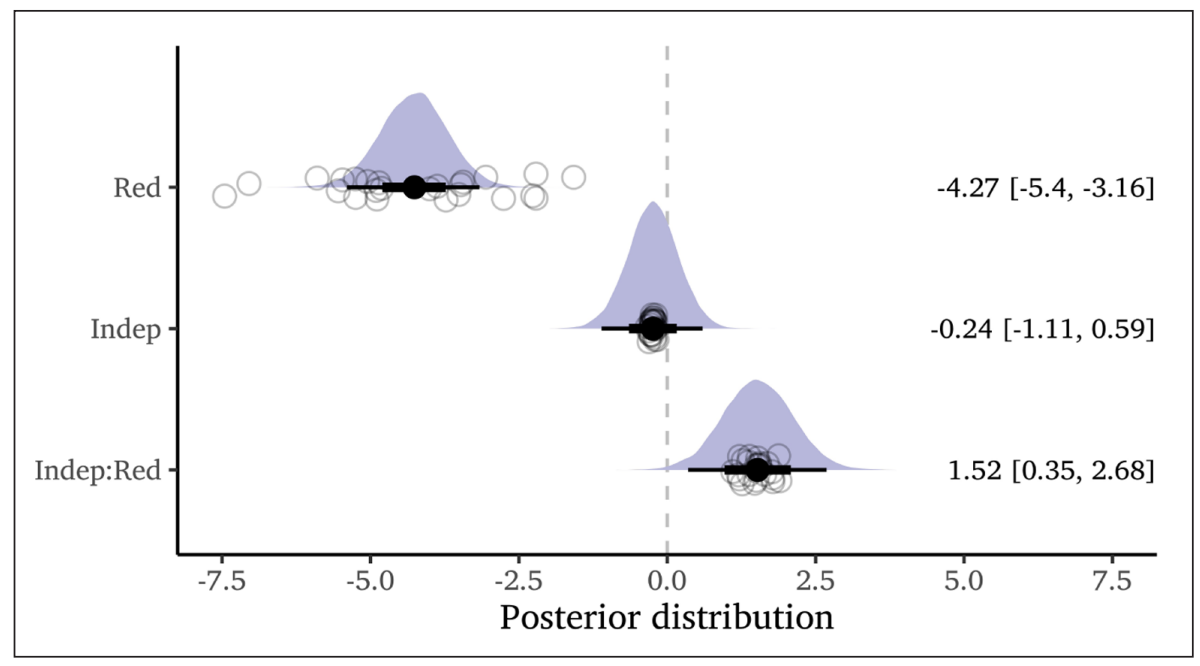

Before examining the estimates in our model, it is important to note that non-reduction and NCE + Dep are our reference levels. As a result, "Red" (i.e., reduction) in Figure 5 must be interpreted relative to non-reduced forms within the NCE + Dep condition. Likewise, "Indep" (i.e., NCE + Indep) in Figure 5 must be interpreted relative to NCE + Dep forms within the non-reduced condition.

The crucial posterior distribution in Figure 5 is "Indep:Red", i.e., the interaction between the two variables in question. We see an entirely positive 95\% HDI, which indicates that participants find reduction more natural in NCE + Indep forms than in NCE + Dep forms-mirroring the
Figure 4 Distribution of responses along a 10-point scale, from "unnatural" (1) to "natural" (10) responses. Means are provided in boxes.

Figure 5 Posterior distributions of model estimates and associated $50 \%$ and $95 \%$ HDIs. Mean estimates and $95 \%$ HDIs values provided-all values are given in log-odds. Gray circles correspond to byspeaker random effects. Positive estimates indicate a concentration of responses on the higher end of the scale. 
pattern observed in Figure 4 (Indep:Red: $\hat{\beta}=1.52,95 \%$ HDI $=[0.35,2.68]$ ). Among NCE + Dep forms, reduced forms have a negative posterior distribution (Red: $\hat{\beta}=-4.27,95 \% \mathrm{HDI}=[-5.4$, -3.16]). This is not surprising, given what we observe in Figure 4: participants find reduced forms less natural for both NCE + Dep and NCE + Indep. Among non-reduced forms, no credible statistical effect is observed for type of NCE structure (NCE + Indep vs NCE + Dep), as shown in the posterior distribution for Indep in Figure 5 (Indep: $\hat{\beta}=-0.24,95 \%$ HDI $=[-1.11,0.59]$ ).

In summary, participants' responses are statistically affected by whether an NCE combines with a prosodically dependent or independent structure. Reduction in NCE + Indep forms (e.g., psicolinguística 'psycholinguistics') is seen as more natural relative to reduction in NCE + Dep forms (e.g., psicologia 'psychology'). In addition to the overall effect shown in Figure 4 and confirmed in Figure 5, the same trend is observed for nearly all participants, as shown in Figure 3. These results are consistent with our predictions, since NCE + Dep and NCE + Indep are indeed rated differently for vowel reduction in the NCE (prediction i), with reduction being more natural in NCE + Indep (prediction ii), and reduction in NCE + Dep attaining only moderate rates of naturalness (prediction ii). In line with the status of NCEs as learned forms, nonreduction is rated as natural for both NCE + Dep and NCE + Indep (prediction iii). Participants' judgements with respect to reduction in NCE + Dep and NCE + Indep thus seem consistent with these structures having distinct prosodic representations, as indicated in (9) and (10), where NCE + Dep corresponds to a single PWd, and NCE + Indep corresponds to a recursive PWd.

However, as the bars in Figure 4 show, participants' responses for reduction in NCEs are not categorical. This might be surprising, especially in the case of NCE + Indep: if the NCE in this structure is a separate PWd, reduction should be rated even higher than it currently is or, alternatively, non-reduction should be rated lower relative to reduction. We return to this issue in the next section.

\subsection{Production data}

The total number of items included in the analysis of production data is $274 .{ }^{14}$ The statistical models have F1, F2 and vowel duration as the response variables, and NCE structure and focus as the main predictors. These models include by-speaker and by-item random interceptsmodels with random slopes were too complex and produced singular fits when run using the lmer() function in R (Bates et al. 2015).

Figure 6 plots the results for F2 (with values centered and standardized by speaker) in both NCE + Dep and NCE + Indep structures. NCE + Indep yielded higher F2 values, confirming our prediction that the target vowel in these structures is more centralized than the target vowel in NCE + Dep, and consistent with previous observations about word-final vowels (MassiniCagliari 1992). The F2 difference between NCE + Indep and NCE + Dep is $120 \mathrm{~Hz}$ (mean F2 for $\mathrm{NCE}+$ Indep $=1325 \mathrm{~Hz}$; mean F2 for NCE + Dep $=1205 \mathrm{~Hz}$; these values are consistent with the F2 ranges observed for final [u] and pretonic/stressed /o/ in Massini-Cagliari (1992)). The effect in question is statistically credible (Indep: $\hat{\beta}=132.42,95 \%$ HDI $=[9.12,255.24]$ )—see Table 5 in Appendix A.3. No statistical effect of focus was found on F2 values (Non-focus: $\hat{\beta}=$ $32.35,95 \%$ HDI $=[-32.18,95.34])$.

An identical model predicting F1 as a function of NCE structure was also run, and no statistically credible effect was found (Indep: $\hat{\beta}=-0.17,95 \%$ HDI $=[-23.12,22.89]$ ), contrary to predictions that the target vowel in NCE + Indep would be higher (as observed for word-final vowels in some studies; e.g., Fails \& Clegg (1992)). In this model, focus also did not have a statistically credible effect on F1 values (Non-focus: $\hat{\beta}=-11.71,95 \%$ HDI $=[-24.04,0.41]$ ). The mean F1 for the target vowel was $517 \mathrm{~Hz}$ in NCE + Dep, and $514 \mathrm{~Hz}$ in NCE + Indep.

No statistically credible effect was found for duration, either (Indep: $\hat{\beta}=-3.3,95 \%$ HDI $=$ $[-13.4,6.8]$; Non-focus: $\hat{\beta}=-4.4,95 \%$ HDI $=[-8.5,-0.4]$; the effect sizes for duration are given in milliseconds). This contrasts with observations that word-final vowels are shorter than pretonic vowels in BP (e.g., Crosswhite 2004; Kenstowicz \& Sandalo 2016; Oh 2019). The mean duration of the target vowel was $56.8 \mathrm{~ms}$ in NCE + Dep, and $53.2 \mathrm{~ms}$ in NCE + Indep. 


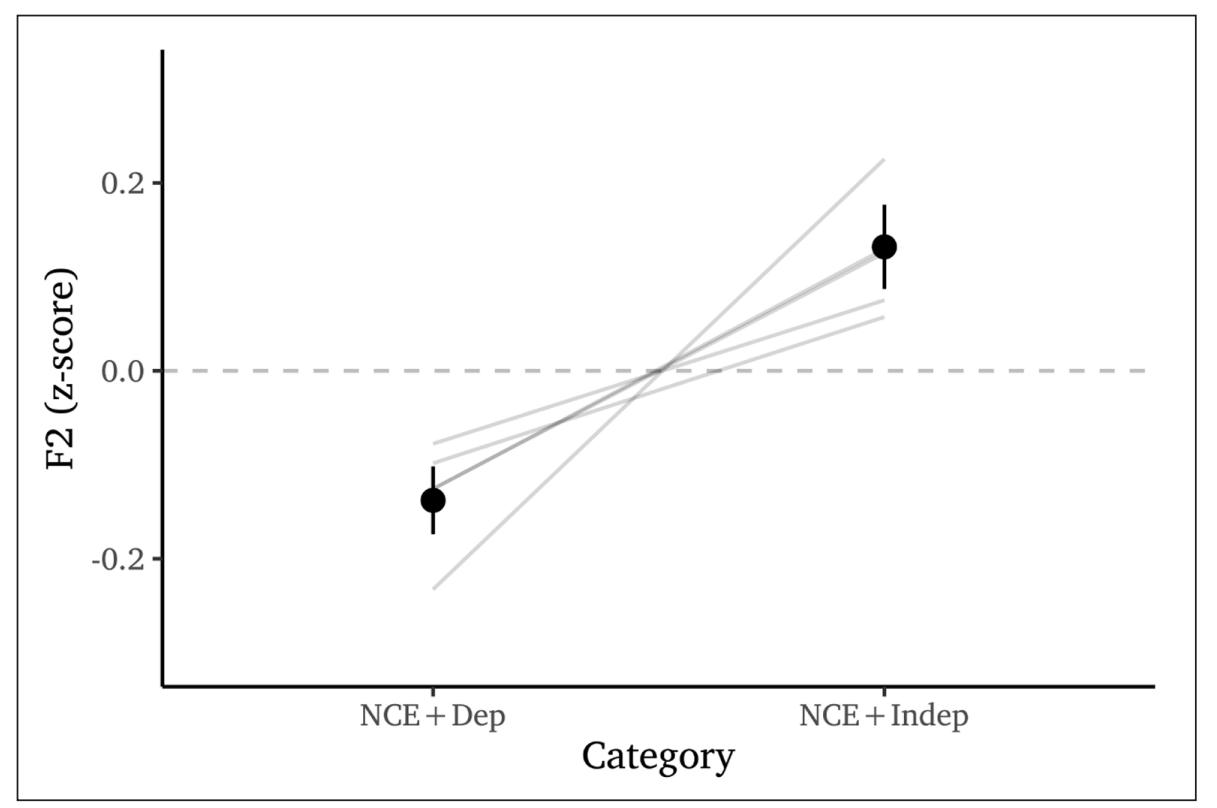

As mentioned above, F2 differentiates NCE + Dep and NCE + Indep. To estimate the rates of reduction for both categories, we employed K-means clustering (Hartigan \& Wong 1979), an unsupervised learning technique that clusters the data into $k$ categories based on a given variable (in this case, F2). K-means minimizes within-cluster variance, that is, the sum of squared Euclidean distances from the center of the cluster. Using standardized F2 from the production data as our variable, and assuming $k=2$ (simulating reduction $v s$. non-reduction), we ran a categorization model for NCE + Dep and NCE + Indep. In the model, the cluster with the higher standardized F2 mean was associated with reduction, as per our discussion above. Later, we calculated the resulting rates of reduction based on these clusters. For NCE + Dep, the rate of reduction was $24 \%$; for NCE + Indep, the rate was $48 \% .{ }^{15}$ This categorization method is statistically principled, and it is not subject to any biases that human listeners might have when judging reduction across the two NCE structures in question.

In summary, judgement and production data indicate that reduction in NCE + Indep structures is not only more acceptable, but also produced more frequently relative to NCE + Dep structures. Regarding production, reduction in NCE + Indep is manifested through centralization of the NCE-final vowel. In the next section, we further discuss whether these judgement and production patterns are consistent with the proposed representations for NCE + Dep and NCE + Indep, and the ways in which prosodic representation may accommodate non-categoricity.

\section{Non-categoricity in the prosodic hierarchy}

In our judgement task, reduction in NCE + Indep has statistically higher ratings than reduction in NCE + Dep. In our production task, the NCE-final vowel exhibits more centralization in NCE + Indep than in NCE + Dep. These results are consistent with (a) the idea that NCE + Indep and NCE + Dep have distinct prosodic representations, and (b) the idea that word-final raising is more pervasive in the BP grammar than raising in pretonic position. In other words, reduction is better and more likely in NCEs that are targeted by word-final raising (i.e., in NCE + Indep, where the NCE is a PWd) than in NCEs that are targeted by raising in pretonic position (i.e, in NCE + Dep, where the NCE is not an independent PWd).

The distribution of participants' judgement responses for reduction in both Figures 3 and 4 indicates that preferences are not categorical for any of the NCE structures under examination. As predicted, ratings for reduction in NCE + Dep are moderate $(\bar{x}=6.5)$, in line with raising in pretonic position being variable and lexically constrained in BP. On the other hand, ratings for reduction in NCE + Indep are substantially higher $(\bar{x}=7.8)$, although they do not reflect the assumed categoricity of word-final raising in BP (e.g., Leite \& Callou 2002; Vieira 2002). In
Figure 6 F2 mean values and associated standard errors ( $y$-axis; $z$-scores) for NCE+Dep and NCE+Indep ( $x$-axis). Lines represent speaker means. 
production, however, NCE-final vowels are more centralized in NCE + Indep than NCE + Dep, which also supports the idea of NCEs being prosodized differently depending on the structure with which they combine.

Our results thus suggest that NCE + Dep and NCE + Indep are in effect targeted by different phonological phenomena. If speakers had the same prosodic representation for both NCE + Dep and NCE + Indep, they should accept or reject reduction in both structures with similar ratings. In the judgement task, what reveals that speakers have distinct representations for NCE structures is not whether or not they accept reduction in both, but rather how acceptable reduction is in these structures. The findings from the judgement task and the production task provide empirical evidence that expands on initial proposals on prosodic differences between NCE structures in BP (section 2.2) based on morphological factors and stress assignment patterns.

As discussed above, other work in Prosodic Phonology has argued that distinct application rates are evidence for different prosodic representations (Guzzo \& Garcia 2020). In Guzzo \& Garcia (2020), however, the structures under examination (pronominal and non-pronominal clitics in BP) differ with respect to the frequency of application of the same process. This contrasts with what is observed in NCE-final vowels, which are targeted by different processes depending on the type of structure that they form.

The results of our judgement task, as well as the results for clitics in Guzzo \& Garcia (2020), suggest that gradient behavior reflects prosodic representations. In other words, prosodic differences may be revealed not only based on whether or not a given phenomenon applies in a specific structure, but also based on how frequently it applies or is accepted by speakers. Following from this, an analysis that accounts for the prosodic differences between NCE + Dep and NCE + Indep by positing that the former is subject to raising in pretonic position while the latter is subject to word-final raising is thus incomplete: since both phenomena involve a similar phonetic outcome, distinguishing between them is contingent on the examination of their frequency of application (or, in the case of our judgement task, their frequency of acceptance).

As shown in (15), the prosodic mapping of NCE + Dep and NCE + Indep is invariable, and reduction rates (in acceptance and production) are predicted on the basis of the resulting prosodic structure. Following from this, reduction in the NCE-final vowel in NCE + Dep is not evidence for the alternative mapping of this structure as NCE + Indep, since some degree of reduction is anticipated in PWd-internal position.

$$
\begin{aligned}
& \text { a. } \quad\left[\text { psikolo' }{ }^{\prime i a}\right]_{\mathrm{PWd}} \\
& \text { moderate acceptance of raising in pretonic position; } \\
& \text { less centralization } \\
& \text { b. } \left.\quad[\text { psiko }]_{\mathrm{PWd}}[\text { lin'gwistika }]_{\mathrm{PWd}}\right]_{\mathrm{PWd}}
\end{aligned}
$$

This contrasts with the proposal for stem + word and word + word compounds in Standard Italian by Peperkamp (1997b, 1997a), which is particularly relevant to our analysis since NCE + Indep structures correspond to stem + word compounds in Peperkamp's account. For both stem + word and word + word compounds in Italian, the raising or preservation of a lower mid vowel in the first element of the compound indicates whether the compound is prosodized as a recursive PWd or as two separate PWds-see (8). Thus, in Peperkamp (1997b, 1997a), there are two prosodic mappings available to these compounds, which are reflected in the way that the lower mid vowel is realized.

While we assume that multiple prosodic mappings may be available for certain structures, we argue that this does not apply to NCEs in BP. The case of compounds in Italian has an important difference relative to the case of NCEs in BP. In Italian, lower mid vowels are only found in primarily stressed syllables. Therefore, raising to upper mid indicates that the vowel has lost its primary stress and thus behaves as a pretonic vowel. Since lower mid vowels and and upper mid vowels alternate in the first element of Italian compounds, it is reasonable to assume that the alternation stems from prosodic differences.

On the other hand, the application of reduction processes in NCEs in BP does not involve the target vowel losing its stress. The mapping of NCE + Dep as a simple PWd provides the structure with context for PWd-internal processes such as pretonic raising and vowel harmony, which are variable in the language (with modest application rates in production, as discussed in 2.1). 
The mapping of NCE + Indep into two PWds creates context for the NCE-final vowel to undergo word-final processes, such as vowel raising. The type of variation exhibited by NCE-final vowels can thus be captured by positing a specific prosodic representation for each NCE structure.

It should be noted that vowel behavior following from prosodic differences in NCEs is also consistent with proposals about reduction within the word domain in BP. Several previous studies have argued that reduction in word-final position is more extreme than reduction in pretonic position, given the smaller vowel inventory in word-final position relative to pretonic position and the quality differences observed for vowels in these two positions (e.g., Barnes 2002; Crosswhite 2004; Kenstowicz \& Sandalo 2016; Oh 2019). While these observations regarding degrees of reduction were based on non-compounds, the results for NCE + Indep suggest that they may be extended to more complex PWd structures.

Although vowel raising in word-final position is categorical in most BP dialects (including standard BP), it was not categorically accepted by speakers in our judgement task. In addition, non-reduction in NCE + Indep obtained a mean acceptance rate higher than the mean acceptance rate for reduction, and equivalent to the acceptance rate of non-reduction in NCE + Dep (see Figure 4). Given that NCEs are learned items and that participants were able to see the written form of the stimuli that they were judging, it is not surprising that non-reduction was rated high for both NCE + Dep and NCE + Indep (orthographic $o$ is typically produced as [o] in BP). What may be surprising, however, is that reduction in NCE + Indep did not reach a higher acceptance rate, one that would be more consistent with the status of word-final raising as a categorical phenomenon in standard BP. Furthermore, in production, reduction in NCE + Indep was signaled only via centralization. While this is a possible correlate for word-final reduction in BP (e.g., Massini-Cagliari 1992), the phenomenon has been shown to also involve raising (e.g., Fails \& Clegg 1992) and shorter vowel duration (e.g., Kenstowicz \& Sandalo 2016).

It is possible that, in NCE + Indep, the non-categorical acceptance rate for reduction and the underuse of phonetic cues to signal reduction are due to the status of the PWd corresponding to the NCE in the recursive PWd. In accounts that assume recursivity within prosodic domains, recursive and non-recursive levels may exhibit distinct phonological behavior. Furthermore, the lower level of a given prosodic domain (i.e., the minimal level) may behave differently from the higher level of the same domain (i.e., the maximal level) (e.g., Ito \& Mester 2009, 2013; Martínez-Paricio 2012; Bennett 2013, 2018; Elfner 2015; Martínez-Paricio \& Kager 2015).

In a framework where levels of a single domain are labeled as maximal and minimal, the PWd corresponding to the NCE and the PWd corresponding to Indep would be minimal PWds $\left(\mathrm{PWd}_{\min }\right)$, while the recursive PWd would be the maximal PWd $\left(\mathrm{PWd}_{\max }\right)$. Given our judgement and production data for reduction in NCE + Indep, it may be the case that word-final raising is manifested differently at the right edges of $\mathrm{PWd}_{\text {max }}$ and $\mathrm{PWd}_{\min }$ (in the case of a $\mathrm{PWd}_{\text {min }}$ that is not the rightmost element of the recursive structure). In other words, word-final raising may be accepted less frequently and cued less strongly at the right edge of $\mathrm{PWd}_{\min }$ relative to the right edge of $\mathrm{PWd}_{\max }$

To examine this possibility, a closer look at the proposed representations for composite structures in BP is needed. NCE + Indep structures pattern prosodically with stressed prefix + word compounds in BP, which have also been argued to correspond to recursive PWds (e.g., Silva 2010; Guzzo 2018). Guzzo (2018) points out that, in stressed prefix + word compounds, the algorithm for word-level secondary stress (variably) reapplies to the structure as a whole. This is the case of a structure such as super-mercado 'supermarket'. Here, stress is penultimate both on the prefix and the following lexical word (súper, mercádo). In the compound, stress on the prefix may shift to the right, yielding the alternating pattern observed for secondary stress in the language: supèr-mercádo. This type of stress shift is not attested in word + word compounds nor phrases in BP (Guzzo 2018). Given this difference in stress patterns, Guzzo (2018) proposes that word + word compounds are prosodized as composite groups (CGs; following e.g., Vogel 2009). ${ }^{16}$ The prosodic structures for NCE+Indep, stressed prefix + word compound and word + word compounds are shown in (16) and (17). 


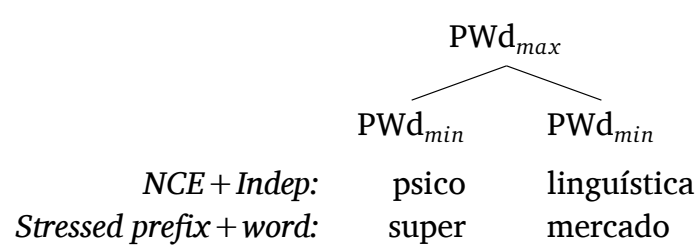

Guzzo and Garcia

Glossa: a journal of

general linguistics

DOI: 10.5334 /gjgl.1413

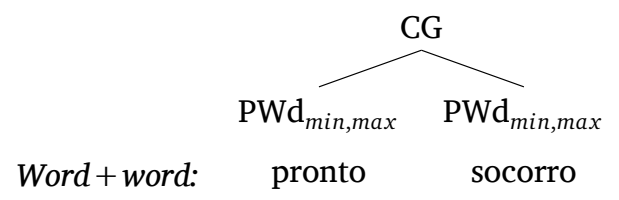

In NCE + Indep, the stress shift observed for stressed prefix + word compounds also seems possible, yielding patterns such as neurò-linguística (from néuro-linguística 'neurolinguistics'), which is consistent with their prosodic representation being identical. In these forms with stress shift, vowel reduction seems to be permitted, as it is in stressed prefix + word compounds. These observations suggest that the secondary stress algorithm in BP operates at the level of the $\mathrm{PWd}_{\max }$

It is important to note, however, that both stressed prefix + word compounds and word + word compounds are assumed to exhibit word-final raising (Silva 2010; Toneli 2014; Guzzo 2018). Expanding on the results of our tasks, it is possible that word-final raising is cued less strongly at the right edge of $\mathrm{PWd}_{\text {min }}$ (which would also explain non-categorical ratings for reduction in $\mathrm{NCE}+$ Indep), and cued more strongly at the right edge of $\mathrm{PWd}_{\max }$. Thus, given the structures in (16) and (17), word-final raising would be cued less strongly in NCEs and stressed prefixes (which are both structure-internal $\mathrm{PWd}_{\text {mins }}$ ), and cued more strongly in the elements of a word + word compound (each of which is both a $\mathrm{PWd}_{\min }$ and a $\mathrm{PWd}_{\max }$ ). ${ }^{17}$

No previous studies on vowel quality in BP seem to include composite structures like those in (16) and (17) in their stimuli, which prevents us from making further comparisons with our own data. Since our primary goal was to examine whether the proposed prosodic differences between NCE + Dep and NCE + Indep hold, we did not include word + word compounds nor stressed prefix + word compounds in our experiment. Further research is thus needed to evaluate whether the patterns of word-final raising in composite structures in BP are in effect consistent with the representations in (16) and (17).

\section{Conclusion}

In this article, we examined vowel reduction in two types of structures with NCEs in BP, namely, NCE + Dep (psicologia) and NCE + Indep (psicolinguística), which have been previously assigned different prosodic representations. While NCE + Dep is assumed to correspond to a simple PWd, NCE + Indep corresponds to a recursive PWd. Given these representations, the NCE-final vowel in NCE + Dep and NCE + Indep is subject to distinct processes: raising in pretonic position in $\mathrm{NCE}+$ Dep, and word-final raising in NCE + Indep. However, since the phonetic outcome of these processes is similar (i.e., an upper mid vowel is reduced to high), it is difficult to evaluate whether the proposed representations for these NCE structures actually hold based solely on whether such vowel processes apply.

We proposed that these potential prosodic differences should be revealed not by the application or non-application of these vowel processes, but rather by how frequently they apply and the extent to which they are accepted by speakers. Given the lexical conditioning of raising in pretonic position, it should be less frequent (both in judgements and in production) than word-final raising. For the structures under analysis, reduction in NCE + Dep should therefore be less frequent than reduction in NCE + Indep. In our judgement task, reduction was in effect judged as more acceptable in NCE + Indep. In production, NCE + Indep exhibited more vowel 
centralization. These patterns are consistent with the proposed prosodic representations for NCE structures in BP. Following from this, we argued that speakers' behavior (in judgements and production) reflect patterns that are predicted by prosodic structure. In our proposal, prosodic structure predicts not only the application or non-application of phonological processes, but also the relative rates at which these processes apply. This proposal may potentially be expanded to the analysis of other (variable) phenomena that seem to involve prosodic conditioning, such as /t, d/ flapping and /1/ velarization in English, and word-final consonant devoicing in German.

\section{A Appendix}

\section{A.1 Stimuli}

\begin{tabular}{|c|c|c|c|}
\hline \multicolumn{2}{|l|}{ NCE+DEP } & \multicolumn{2}{|l|}{ NCE+INDEP } \\
\hline STIMULUS & GLOSS & StIMULUS & GLOSS \\
\hline agro-nomia & ‘agronomy' & agro-negócio & 'agribusiness' \\
\hline eletro-cutado & 'electrocuted' & agro-pecuária & 'farming' \\
\hline hidro-cefalia & ‘hydrocephaly' & agro-tóxico & 'pesticide' \\
\hline hidro-grafia & ‘hydrography' & eletro-doméstico & 'household appliance' \\
\hline hidro-pônico & ‘hydroponic' & eletro-magnetismo & 'electromagnetism' \\
\hline hidro-via & ‘waterway' & eletro-terapia & ‘electrotherapy’ \\
\hline neuro-logia & ‘neurology’ & hidro-ginástica & ‘water aerobics’ \\
\hline orto-dontia & 'orthodontics' & hidro-massagem & 'hot tub' \\
\hline orto-grafia & 'orthography' & hidro-terapia & ‘hydrotherapy’ \\
\hline orto-pedista & 'orthopedist' & neuro-cientista & ‘neuroscientist' \\
\hline proto-zoário & 'protozoan' & neuro-cirurgião & ‘neurosurgeon’ \\
\hline psico-délico & 'psychedelic' & orto-molecular & 'orthomolecular' \\
\hline psico-grafia & ‘psychography' & proto-língua & ‘protolanguage’ \\
\hline psico-logia & ‘psychology’ & psico-linguística & ‘psycholinguistics' \\
\hline psico-pata & ‘psychopath’ & psico-social & ‘psychosocial' \\
\hline psico-trópico & 'psychotropic' & psico-terapia & 'psychotherapy' \\
\hline
\end{tabular}

\section{A.2 Fillers}

\begin{tabular}{|c|c|c|c|}
\hline agrade cido & 'thankful' & mochila & 'backpack' \\
\hline ameaç̧a & 'threat' & mostarda & ‘mustard’ \\
\hline antecipado & ‘anticipated' & pedido & ‘order' \\
\hline aposentadoria & 'retirement' & pedrada & 'blow with stone' \\
\hline assoviar & 'to whistle' & pendurado & ‘hung' \\
\hline bebida & 'drink (n.)’ & penteado & ‘hairstyle' \\
\hline bochecha & 'cheek' & $\mathrm{p}[\underline{\mathrm{e}}] \mathrm{neu}$ & 'tire' \\
\hline bolacha & ‘cookie' & pequeno & ‘small' \\
\hline borboleta & 'butterfly' & percussão & 'percussion' \\
\hline bondade & 'kindness' & perigo & 'danger' \\
\hline carregador & 'charger' & poderoso & 'powerful' \\
\hline cidadezinha & 'city.DIM' & policiamento & 'policing' \\
\hline
\end{tabular}

Table 2 Target stimuli (orthographic form).

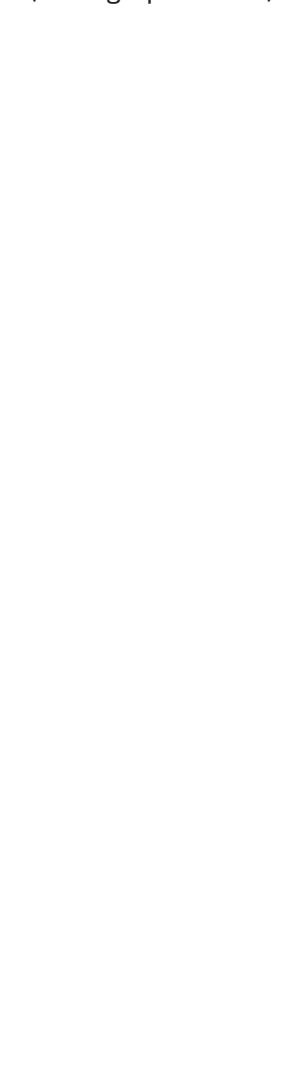

Table 3 Fillers (orthographic form). Vowels with/without reduction are underlined. 


\begin{tabular}{|c|c|c|c|}
\hline comentário & 'comment' & preservado & 'preserved' \\
\hline comida & 'food' & procurado & 'searched' \\
\hline destaque & ‘highlight’ & progresso & ‘progress' \\
\hline devagar & ‘slowly' & repetir & 'to repeat' \\
\hline elevador & ‘elevator’ & rẹprodução & ‘reproduction' \\
\hline enforcar & 'to hang' & roncar & 'to snore' \\
\hline geração & 'generation' & suavemente & 'smoothly' \\
\hline governador & 'governor' & temerosa & 'fearful' \\
\hline hospital & ‘hospital’ & testado & 'tested' \\
\hline martelada & 'blow with hammer' & toppete & ‘crest' \\
\hline medonho & 'fearsome' & torcedor & ‘supporter' \\
\hline menino & ‘boy’ & & \\
\hline
\end{tabular}

\section{A.3 Model estimates}

\begin{tabular}{llllllll}
\hline & ESTIMATE & EST.ERROR & L-95\% CI & U-95\% CI & $\hat{R}$ & BULK ESS & TAIL ESS \\
\hline Intercept[1] & -6.73 & 0.50 & -7.71 & -5.76 & 1.00 & 4845 & 8683 \\
\hline Intercept[2] & -6.24 & 0.49 & -7.21 & -5.28 & 1.00 & 4768 & 8663 \\
\hline Intercept[3] & -5.74 & 0.49 & -6.70 & -4.79 & 1.00 & 4741 & 8223 \\
\hline Intercept[4] & -5.40 & 0.48 & -6.35 & -4.45 & 1.00 & 4743 & 8516 \\
\hline Intercept[5] & -4.86 & 0.48 & -5.81 & -3.91 & 1.00 & 4717 & 8361 \\
\hline Intercept[6] & -4.42 & 0.48 & -5.37 & -3.48 & 1.00 & 4701 & 8128 \\
\hline Intercept[7] & -3.83 & 0.48 & -4.77 & -2.89 & 1.00 & 4665 & 7987 \\
\hline Intercept[8] & -3.01 & 0.47 & -3.95 & -2.08 & 1.00 & 4628 & 8075 \\
\hline Intercept[9] & -2.32 & 0.47 & -3.26 & -1.40 & 1.00 & 4606 & 8459 \\
\hline Indep & -0.24 & 0.43 & -1.11 & 0.59 & 1.00 & 5557 & 10006 \\
\hline Red & -4.27 & 0.57 & -5.40 & -3.16 & 1.00 & 5449 & 9427 \\
\hline Indep:Red & 1.52 & 0.59 & 0.35 & 2.68 & 1.00 & 4600 & 8735 \\
\hline
\end{tabular}

Table 4 Judgement task: Model estimates and associated errors, 95\% credible intervals, $\hat{R}$, and effective sample sizes (ESS).

\begin{tabular}{llllllll}
\hline & EStIMATE & EST.ERROR & L-95\% CI & $\mathbf{U}-95 \% \mathrm{Cl}$ & $\hat{\mathbf{R}}$ & BuLK ESS & TAIL ESS \\
\hline Intercept & 1147.28 & 90.85 & 968.51 & 1325.53 & 1.00 & 1854 & 2157 \\
\hline Indep & 132.42 & 63.80 & 9.12 & 255.24 & 1.00 & 1923 & 2461 \\
\hline Focus & 32.35 & 32.64 & -32.18 & 95.34 & 1.00 & 7137 & 2751 \\
\hline
\end{tabular}

Table 5 Production task (F2): Model estimates and associated errors, 95\% credible intervals, $\hat{R}$, and effective sample sizes (ESS).

\section{Abbreviations}

$\mathrm{BP}=$ Brazilian Portuguese, $\mathrm{CG}=$ composite group, DIM = diminutive, $\mathrm{CI}=$ credible interval, $\mathrm{ESS}=$ effective sample size, $\mathrm{HDI}=$ highest density interval, $\mathrm{NCE}=$ neoclassical element, $\mathrm{PPh}$ $=$ phonological phrase, $\mathrm{PWd}=$ phonological word, $\hat{\mathrm{R}}=$ Gelman-Rubin statistic

\section{Acknowledgements}

We would like to thank three anonymous reviewers and the Associate Editor, Juliet Stanton, for their helpful comments and suggestions. We would also like to thank Heather Goad for invaluable discussion on prosodic representation, and Matthew Siegel for research assistantship. 


\section{Competing Interests}

The authors have no competing interests to declare.

\section{Author affiliations}

Natália Brambatti Guzzo (D) orcid.org/0000-0003-2876-2173

McGill University, Department of Linguistics, CA

Guilherme Duarte Garcia (D) orcid.org/0000-0003-1412-3856

Ball State University, Department of English, US

\section{References}

Barnes, J. 2002. Positional Neutralization: A Phonologization Approach to Typological Patterns. University of California at Berkeley dissertation.

Barr, Dale, Roger Levy, Christoph Scheepers \& Hal Tily. 2013. Random effects structure for confirmatory hypothesis testing: Keep it maximal. Journal of Memory and Language 68(3). 255-278. DOI: https:// doi.org/10.1016/j.jml.2012.11.001

Bates, Douglas, Martin Mächler, Ben Bolker \& Steve Walker. 2015. Fitting linear mixed-effects models using lme4. Journal of Statistical Software 67(1). 1-48. DOI: https://doi.org/10.18637/jss.v067.i01

Battisti, Elisa. 1993. Elevação das vogais médias pretônicas em sílaba inicial de vocábulo na fala gaúcha [Raising of pretonic mid vowels in word-initial syllable in southern Brazil]. Universidade Federal do Rio Grande do Sul MA thesis.

Bauer, Laurie. 1998. Is there a class of neoclassical compounds, and if so is it productive? Linguistics 36(3). 403-422. DOI: $h$ ttps://doi.org/10.1515/ling.1998.36.3.403

Bennett, Ryan. 2013. The uniqueness of metrical structure: Rhythmic phonotactics in Huariapano. Phonology, 355-398. DOI: https://doi.org/10.1017/S0952675713000195

Bennett, Ryan. 2018. Recursive prosodic words in Kaqchikel (Mayan). Glossa: A journal of general linguistics 3(1). DOI: https://doi.org/10.5334/gigl.550

Bisol, Leda. 1981. Harmonia vocálica: uma regra variável [Vowel harmony: a variable rule]. Universidade Federal do Rio de Janeiro dissertation.

Bisol, Leda. 1989. Vowel harmony: a variable rule in Brazilian Portuguese. Language Variation and Change 1. 185-198. DOI: https://doi.org/10.1017/S0954394500000065

Bisol, Leda. 2005. O clítico e seu hospedeiro [The clitic and its host]. Letras de Hoje 40(3). 163-184.

Bisol, Leda. 2009. O alçamento da pretônica sem motivação aparente [Unmotivated raising of pretonic mid vowels]. In Leda Bisol \& Gisela Collischonn (eds.), Português do sul do Brasil: variação fonológica [Southern Brazilian Portuguese: phonological variation]. Porto Alegre: EDIPUCRS.

Bisol, Leda \& João Veloso. 2016. Phonological processes affecting vowels: neutralization, harmony and nasalization. In W. Leo Wetzels, João Costa \& Sergio Menuzzi (eds.), The handbook of Portuguese linguistics, 69-85. Malden, MA: Wiley. DOI: https://doi.org/10.1002/9781118791844.ch5

Blumenfeld, Lev. 2011. Phonology. Vowel-zero alternations in Russian prepositions: Prosodic constituency and productivity. In Veronika Makarova (ed.), Russian language studies in North America: New perspectives from theoretical and applied linguistics, 43-70. New York, NY: Anthem Press. DOI: https:// doi.org/10.7135/UPO9780857286505.003

Boersma, Paul \& David Weenink. 2020. Praat: doing phonetics by computer [Computer program].

Callou, Dinah, Yonne Leite \& Lilian Coutinho. 1991. Elevação e abaixamento das vogais prêtonicas no dialeto do rio de janeiro [Raising and lowering of pretonic vowels in the Rio de Janeiro dialect]. Organon 18. 71-78.

Callou, Dinah, Yonne Leite \& João Moraes. 2002. A elevação das vogais pretônicas no português do Brasil: processo(s) de variação estável [Pretonic raising in Brazilian Portuguese: stable processes]. Letras de Hoje 37(1). 9-24.

Câmara Jr., Joaquim Mattoso. 1970. Estrutura da língua portuguesa [The structure of Portuguese]. Petrópolis: Editora Vozes.

Carpenter, Bob, Andrew Gelman, Matthew Hoffman, Daniel Lee, Ben Goodrich, Michael Betancourt, Marcus Brubaker, Jiqiang Guo, Peter Li \& Allen Riddell. 2017. Stan: a probabilistic programming language. Journal of Statistical Software, Articles 76(1). 1-32. https://www.jstatsoft.org/v076/i01. DOI: https://doi.org/10.18637/jss.v076.i01

Chomsky, N. \& M. Halle. 1968. The sound pattern of English. New York: Harper \& Row. Crosswhite, Katherine. 2004. Vowel reduction. In Bruce Hayes, Robert Kirchner \& Donca Steriade (eds.), Phonetically based phonology, 191-231. Cambridge: Cambridge University Press.

Elfner, Emily. 2015. Recursion in prosodic phrasing: Evidence from Connemara Irish. Natural Language \& Linguistic Theory 33(4). 1169-1208. DOI: https://doi.org/10.1007/s11049-014-9281-5 
Fails, C. Willis \& J. Halvor Clegg. 1992. A spectrographic analysis of Portuguese stressed and unstressed vowels. In Donaldo P. Macedo \& Dale A. Koike (eds.), Romance linguistics: the Portuguese context, 31-42.

Gelman, Andrew, Jessica Hwang \& Aki Vehtari. 2014. Understanding predictive information criteria for Bayesian models. Statistics and Computing 24(6). 997-1016. DOI: https://doi.org/10.1007/s11222013-9416-2

Graebin, Geruza de Souza. 2008. A fala de Formosa/GO: a pronúncia das vogais medias pretônicas [The speech of Formosa/GO: the pronunciation of pretonic mid vowels]. Universidade de Brasília MA thesis.

Guzzo, Natália Brambatti. 2018. The prosodic representation of composite structures in Brazilian Portuguese. Journal of Linguistics 54. 683-720. DOI: https://doi.org/10.1017/S0022226718000099

Guzzo, Natália Brambatti \& Guilherme Duarte Garcia. 2020. Phonological variation and prosodic representation: Clitics in Portuguese-Veneto contact. Journal of Language Contact 13. 389-427. DOI: https://doi.org/10.1177/0267658319882457

Hartigan, J. A. \& M. A. Wong. 1979. Algorithm AS 136: A K-means clustering algorithm. Journal of the Royal Statistical Society. Series C (Applied Statistics) 28(1). 100-108. DOI: https://doi. org/10.2307/2346830

Hayes, Bruce. 1989. The prosodic hierarchy in meter. In Kiparsky, Paul \& Youmans, G. (eds.), Rhythm and meter, 201-260. Orlando: Academic Press. DOI: https://doi.org/10.1016/B978-0-12-4093409.50013-9

Inkelas, Sharon. 1989. Prosodic Constituency in the Lexicon. Stanford University dissertation. Published 1990, Outstanding Dissertations in Linguistics Series. New York: Garland Press.

Ito, Junko \& Armin Mester. 2009. The extended prosodic word. In Janet Grijzenhout \& Baris Kabak (eds.), Phonological domains: Universals and deviations, 135-194. Berlin: Mouton de Gruyter. DOI: https://doi. org/10.1515/9783110219234.2.135

Ito, Junko \& Armin Mester. 2013. Prosodic subcategories in Japanese. Lingua 124. 20-40. DOI: https:// doi.org/10.1016/j.lingua.2012.08.016

Kabak, Baris \& Anthi Revithiadou. 2009. An interface approach to prosodic word recursion. In Janet Grijzenhout \& Baris Kabak (eds.), Phonological domains: Universals and deviations, 105-133. Berlin: Mouton de Gruyter. DOI: https://doi.org/10.1515/9783110219234.2.105

Kenstowicz, Michael \& Filomena Sandalo. 2016. Pretonic vowel reduction in Brazilian Portuguese: Harmony and dispersion. Journal of Portuguese Linguistics 15. 1-19. DOI: https://doi.org/10.5334/jpl.7

Ladd, D. Robert. 1986. Intonational phrasing: The case for recursive prosodic structure. Phonology 3. 311-340. DOI: https://doi.org/10.1017/S0952675700000671

Leite, Yonne \& Dinah Callou. 2002. Como falam os brasileiros [How Brazilians speak]. Rio de Janeiro: Zahar.

Lionnet, Florian. 2019. The colon as a separate prosodic category: tonal evidence from Paicî (Oceanic, Nova Caledonia). In Proceedings of the 36th West Coast Conference on Formal Linguistics, 250-259.

Lüdeling, Anke. 2006. Neoclassical word-formation. In Encyclopedia of language and linguistics, $2 \mathrm{nd}$ edn.

Lüdeling, Anke, Tanja Schmid \& Sawwas Kiokpasoglou. 2002. Neoclassical word formation in German. In Geert Booij \& Jaap van Marle (eds.), Yearbook of morphology 2001, 253-283. DOI: https://doi. org/10.1007/978-94-017-3726-5_10

Major, Roy C. 1985. Stress and rhythm in Brazilian Portuguese. Language 61(2). 259-282. DOI: https:// doi.org/10.2307/414145

Martínez-Paricio, Violeta. 2012. Superfeet as recursion. In Proceedings of the 30th West Coast Conference on Formal Linguistics (WCCFL 30), University of California, Santa Cruz, USA.

Martínez-Paricio, Violeta \& René Kager. 2015. The binary-to-ternary rhythmic continuum in stress typology: Layered feet and non-intervention constraints. Phonology 32(3). 459-504. DOI: https://doi. org/10.1017/S0952675715000287

Massini-Cagliari, Gladis. 1992. Acento e ritmo [Stress and rhythm]. São Paulo: Editora Contexto.

Miller, Taylor L. 2018. Polysynthesis at the phonology-syntax interface: a case study of Kiowa and Salteaux Ojibwe. Newark, DE: University of Delaware dissertation.

Miller, Taylor L. 2020. Navigating the phonology-syntax interface and Tri-P mapping. In Proceedings of the 2019 Annual Meeting on Phonology. DOI: https://doi.org/10.3765/amp.v8i0.4718

Miller, Taylor L. \& Hannah Sande. 2021. Is word-level recursion actually recursion? Manuscript.

Nespor, Marina \& Irene Vogel. 1986. Prosodic phonology. Dordrecht: Foris.

Oh, Sejin. 2019. Phonetic and phonological vowel reduction in Brazilian Portuguese. In Proceedings of the 19th International Congress of Phonetic Sciences, Melbourne, Australia.

Oliveira, Marco Antônio de. 1992. Aspectos da difusão lexical [Aspects of lexical diffusion]. Revista de Estudos da Linguagem 1. 31-41. DOI: https://doi.org/10.17851/2237-2083.1.1.31-41

Peperkamp, Sharon. 1997a. The prosodic structure of compounds. In Matos, Gabriela, Miguel, Matilde, Duarte, Inês \& Faria, Isabel Hub (eds.), Interfaces in linguistic theory, 259-279. APL/Colibri.

Peperkamp, Sharon. 1997b. Prosodic words. The Hague: Holland Academic Graphics. University of Amsterdam dissertation. 
R Core Team. 2020. R: a language and environment for statistical computing. Vienna, Austria: R Foundation for Statistical Computing. http://www.R-project.org/.

Roveda, Suzana Damiani. 1998. Elevação da vogal média átona final em comunidades bilíngues: português e italiano [Raising of unstressed final mid vowels in bilingual communities: Portuguese and Italian]. Pontifícia Universidade Católica do Rio Grande do Sul MA thesis.

Scalise, Sergio. 1986. Generative morphology. Dordrecht: Foris. DOI: https://doi. org/10.1515/9783110877328

Schwindt, Luiz Carlos. 2001. O prefixo no português brasileiro: análise prosódica e lexical [The prefix in Brazilian Portuguese: a prosodic and lexical analysis]. DELTA: Documentação de Estudos em Lingüística Teórica e Aplicada 17(2). 175-207. DOI: https://doi.org/10.1590/S0102-44502001000200001

Schwindt, Luiz Carlos. 2002. A regra variável de harmonização vocálica no RS [The variable vowel harmony rule in RS, Brazil]. In Leda Bisol \& Cláudia Brescancini (eds.), Fonologia e variação: recortes do português brasileiro [Phonology and variation: snapshots of Brazilian Portuguese].

Selkirk, Elisabeth. 1980. The role of prosodic categories in English word stress. Linguistic Inquiry 11(3). 563-605.

Selkirk, Elisabeth. 1984. Phonology and Syntax: The Relation between Sound and Structure. Cambridge, MA: MIT Press.

Selkirk, Elisabeth. 1986. On derived domains in sentence phonology. Phonology 3. 371-405. DOI: https:// doi.org/10.1017/S0952675700000695

Selkirk, Elisabeth. 1996. The prosodic structure of function words. In James L. Morgan \& Katherine Demuth (eds.), Signal to syntax: Bootstrapping from speech to grammar in early acquisition, 187-214. Lawrence Erlbaum Associates.

Selkirk, Elisabeth. 2011. The syntax-phonology interface. In J. Goldsmith, J. Riggle \& A. Yu (eds.), The handbook of phonological theory, 435-483. Oxford: Blackwell $2^{\text {nd }}$ edn. DOI: https://doi. org/10.1002/9781444343069.ch14

Silva, Taís Bopp da. 2010. Formação de palavras compostas em Português Brasileiro: uma análise de interfaces [Compound word formation in Brazilian Portuguese: an interface analysis]. Universidade Federal do Rio Grande do Sul dissertation.

Tang, Kevin. 2012. A 61 million word corpus of Brazilian Portuguese film subtitles as a resource for linguistic research. UCL Working Papers in Linguistics 24. 208-214.

Toneli, Priscila Marques. 2014. A palavra prosódica no português brasileiro [The prosodic word in Brazilian Portuguese]. Universidade Estadual de Campinas dissertation.

Topintzi, Nina. 2017. The prosodic colon in stress, tone and prosodic templates: evidence from Iquito and elsewhere. In Selected papers from the 22nd International Symposium on Theoretical and Applied Linguistics, 466-479.

Vieira, Maria José Blaskovski. 2002. As vogais médias postônicas: uma análise variacionista [Post-tonic mid vowels: a variationist analysis]. In Leda Bisol \& Cláudia Brescancini (eds.), Fonologia e variação: recortes do português brasileiro [Phonology and variation: snapshots of Brazilian Portuguese], 127-159. Porto Alegre: EDIPUCRS.

Vieira, Maria José Blaskovski. 2009. As vogais médias átonas nas três capitais do sul do País [Unstressed vowels in the three capital cities of southern Brazil]. In Leda Bisol \& Cláudia Brescancini (eds.), Português do sul do Brasil: variação fonológica [Southern Brazilian Portuguese: phonological variation], 45-62. Porto Alegre: EDIPUCRS.

Vigário, Marina. 2010. Prosodic structure between the prosodic word and the phonological phrase: recursive nodes or an independent domain? Linguistic Review 27. 485-530. DOI: https://doi. org/10.1515/tlir.2010.017

Vogel, Irene. 2008. The morphology-phonology interface: isolating to polysynthetic languages. Acta Linguistica Hungarica 55(1). 205-226. DOI: https://doi.org/10.1556/ALing.55.2008.1-2.11

Vogel, Irene. 2009. The status of the clitic group. In Janet Grijzenhout \& Baris Kabak (eds.), Phonological domains: Universals and deviations, 15-46. Berlin: Mouton de Gruyter. DOI: https://doi. org/10.1515/9783110219234.1.15

Vogel, Irene. 2010. The phonology of compounds. In Sergio Scalise \& Irene Vogel (eds.), Crossdisciplinary issues in compounding, 145-163. Amsterdam: John Benjamins.

Vogel, Irene. 2019. Life after the Strict Layer Hypothesis: prosodic structure geometry. In Hongming Zhang \& Youyong Qian (eds.), Prosodic studies: challenges and prospects, 9-60. London: Routledge. DOI: https://doi.org/10.4324/9781351212878-2

Vogel, Irene, Angeliki Athanasopoulou \& Nadya Pincus. 2015. Acoustic properties of prominence in Hungarian and the Functional Load Hypothesis. In Katalin É. Kiss, Balázs Surányi \& Éva Dekány (eds.), Approaches to Hungarian 14. 267-292. Amsterdam: John Benjamins. DOI: https://doi. org/10.1075/atoh.14.11vog

Wagner, Michael. 2010. Prosody and recursion in coordinate structures and beyond. Natural Language \& Linguistic Theory 28(1). 183-237. DOI: https://doi.org/10.1007/s11049-009-9086-0 
Watanabe, Sumio. 2013. A widely applicable Bayesian information criterion. Journal of Machine Learning Research 14. 867-897.

Wetzels, W. Leo. 1992. Mid vowel neutralization in Brazilian Portuguese. Cadernos de Estudos Linguísticos 23. 19-55. DOI: https://doi.org/10.20396/cel.v23i0.8636844

Zec, Draga. 2005. Prosodic differences among function words. Phonology 22(01). DOI: https://doi. org/10.1017/S0952675705000448
TO CITE THIS ARTICLE:

Guzzo, Natália Brambatti and Guilherme Duarte Garcia. 2021. Gradience in prosodic representation: vowel reduction and neoclassical elements in Brazilian Portuguese. Glossa: a journal of general linguistics 6(1): 74. 1-26. DOI: https://doi. org/10.5334/gjgl.1413

Submitted: 19 August 2020 Accepted: 06 May 2021 Published: 02 June 2021

COPYRIGHT:

(c) 2021 The Author(s). This is an open-access article distributed under the terms of the Creative Commons Attribution 4.0 International License (CC-BY 4.0), which permits unrestricted use, distribution, and reproduction in any medium, provided the original author and source are credited. See http:// creativecommons.org/ licenses/by/4.0/.

Glossa: a journal of general linguistics is a peer-reviewed open access journal published by Ubiquity Press. 